OPEN ACCESS

Edited by:

Rebecca Ann Wingert,

University of Notre Dame,

United States

Reviewed by:

Janel Kopp

University of British Columbia, Canada

Ling-Qing Yuan,

Central South University, China

*Correspondence:

Marc P. Stemmler marc.stemmler@fau.de Isabell Armstark

isabell.armstark@fau.de

Specialty section:

This article was submitted to Molecular and Cellular Pathology, a section of the journal Frontiers in Cell and Developmental Biology

Received: 04 August 2021 Accepted: 27 October 2021 Published: 23 November 2021

Citation: van Roey $R$, Brabletz T, Stemmler MP and Armstark I (2021) Deregulation of Transcription Factor Networks Driving Cell Plasticity and Metastasis in

Pancreatic Cancer. Front. Cell Dev. Biol. 9:753456. doi: 10.3389/fcell.2021.753456

\section{Deregulation of Transcription Factor Networks Driving Cell Plasticity and Metastasis in Pancreatic Cancer}

\author{
Ruthger van Roey, Thomas Brabletz, Marc P. Stemmler* and Isabell Armstark*
}

Department of Experimental Medicine 1, Nikolaus-Fiebiger Center for Molecular Medicine, Friedrich-Alexander University of Erlangen-Nürnberg, Erlangen, Germany

Pancreatic cancer is a very aggressive disease with 5-year survival rates of less than $10 \%$. The constantly increasing incidence and stagnant patient outcomes despite changes in treatment regimens emphasize the requirement of a better understanding of the disease mechanisms. Challenges in treating pancreatic cancer include diagnosis at already progressed disease states due to the lack of early detection methods, rapid acquisition of therapy resistance, and high metastatic competence. Pancreatic ductal adenocarcinoma, the most prevalent type of pancreatic cancer, frequently shows dominant-active mutations in KRAS and TP53 as well as inactivation of genes involved in differentiation and cell-cycle regulation (e.g. SMAD4 and CDKN2A). Besides somatic mutations, deregulated transcription factor activities strongly contribute to disease progression. Specifically, transcriptional regulatory networks essential for proper lineage specification and differentiation during pancreas development are reactivated or become deregulated in the context of cancer and exacerbate progression towards an aggressive phenotype. This review summarizes the recent literature on transcription factor networks and epigenetic gene regulation that play a crucial role during tumorigenesis.

Keywords: ADM-acinar to ductal metaplasia, PanIN-pancreatic intraepithelial neoplasia, PDAC-pancreatic ductal adenocarcinoma, transcription factors (TFs), cellular plasticity, epigenetics (chromatin remodelling), development

\section{INTRODUCTION}

Patients suffering from pancreatic cancer $(\mathrm{PaCa})$ have the lowest overall survival rate compared to other cancer types in Europe, with roughly 7\% surviving over 5-years (European Comission, 2020). Although rated as the ninth most common cancer in Europe, it is currently the fourth most common cause of cancer-related deaths and expected to rank even higher by 2025 (Ferlay et al., 2016). Despite the emergence of new treatment regimens, average survival rates only marginally increased in the past decades. The most prevalent form of $\mathrm{PaCa}$ is pancreatic ductal adenocarcinoma (PDAC), accounting for $90 \%$ of all diagnosed cases. Different PDAC precursor lesions have been identified with pancreatic intraepithelial neoplasia (PanINs) accounting for the major lesions which continuously progress through distinct stages (Hruban et al., 2007; Macgregor-Das and Iacobuzio-Donahue, 2013). Lineage tracing in mice revealed that acinar cells undergoing acinarto-ductal metaplasia (ADM) have the greatest propensity to form PanINs, whereas an ADM-PanINPDAC route in human PaCa is still controversial (Kopp et al., 2012; Storz, 2017). Mutational events driving PDAC formation have been identified, such as genetic alterations in the proto-oncogenic KRAS in early PanIN lesions, inactivation of the tumor suppressor gene CDKN2A in intermediate/ 
late lesions, and mutations in TP53 and SMAD4 during the transition to carcinoma (Goggins et al., 2000; Wilentz et al., 2000; Lüttges et al., 2001). Unfortunately, none of these genetic mutations have yet been proven targetable.

The main problem of PDAC is its early propensity towards metastasis together with the lack of early-stage diagnosis and limited treatment options due to rapid acquisition of therapy resistance. Besides the described genetic alterations, early malignancy and resistance are dependent on dysregulated epigenetic and transcriptional networks. These deregulations promote cellular plasticity, which helps tumor cells to adapt to novel environmental challenges during the metastatic cascade, to evade intrinsic control mechanisms, and dampen therapeutic efficacy (Orth et al., 2019). For a better prediction of disease progression and stratification of patient treatments, transcriptional profiling of resected PDAC tumors led to the identification of different molecular PDAC subtypes. Of those, two major subtypes with high tumor cellularity were described: pancreatic progenitor/classical and squamous/quasimesenchymal/basal-like (Collisson et al., 2011; Moffitt et al., 2015; Bailey et al., 2016; Puleo et al., 2018). Among these subtypes, the squamous type confers the most dismal prognosis and is associated with loss of endodermal cell fate (Bailey et al., 2016). In addition, this subtype is poorlydifferentiated and highly chemoresistant (Chan-Seng-Yue et al., 2020). In contrast, the pancreatic progenitor subtype shows enrichment for the corresponding endodermal markers with a slightly better prognosis and is well-to-moderately differentiated (Bailey et al., 2016). Different samples from the same patient indicated that the pancreatic progenitor and squamous subtype can co-exist within the same tumor (Hayashi et al., 2021). Moreover, these subtypes are highly plastic and can interconvert, making it even more challenging to identify specific markers and subtype-specific treatment regimens (Lomberk et al., 2018; Brunton et al., 2020)

Transcription factors (TFs) are important actors in the spatio-temporal regulation of gene expression by directly binding cis-regulatory genomic elements (promoters and enhancers), recruiting cofactors (activators or repressors), and the core transcriptional machinery (Lee and Young, 2013). Together with other gene regulatory mechanisms, they drive cellular gene expression to orchestrate vital biological processes such as development, differentiation, cell cycle progression, tissue homeostasis, and cellular identity in a complex and tightly controlled manner. Deregulation of the delicate TF networks is a major cause of cancer and many other human diseases (Furney et al., 2006; Lee and Young, 2013). Specifically, TFs play a central role in all six hallmarks of cancer, i.e. sustained angiogenesis, endless replication, resisting cell death, insensitivity to anti-growth signals, self-sufficiency in growth signals, and activating invasion and metastasis (Hanahan and Weinberg, 2000, 2011). Of note, a staggering $20 \%$ of oncogenes encode TFs and TFs are terminal effectors in oncogenic signaling, thus representing important mediators in cancer (Lambert et al., 2018).

Several TFs orchestrating pancreatic organogenesis and driving pancreatic cell identity are deregulated in PDAC, strongly contributing to disease onset and progression. In the current review, we present an overview of our current understanding of transcriptional regulatory networks crucial in pancreas development, tissue homeostasis, and focus on recent findings illustrating how dysregulation of transcriptional networks promotes PDAC pathogenesis. In addition, we discuss the status of therapeutic strategies to target deregulated transcriptional networks and promising perspectives for the future.

\section{TRANSCRIPTION FACTORS THAT ORCHESTRATE PANCREAS ORGANOGENESIS}

The pancreas in the adult is comprised of an exocrine and endocrine compartment. Acini make up $90 \%$ of the cells in the mature organ and secrete nutrient-digestive zymogens, that are collected by a branched network of intralobular ducts for the release into the duodenum (Larsen and Grapin-Botton, 2017; Atkinson et al., 2020; Lorberbaum et al., 2020). The endocrine cells comprise $1-2 \%$ of the organ, are organized in islets of Langerhans and synthesize peptide hormones. They are essential for regulating blood glucose levels, produced by $\alpha$ and $\beta$-cells, the main endocrine cell types that produce Glucagon and Insulin, respectively (Pan and Wright, 2011; Bastidas-Ponce et al., 2017; Larsen and Grapin-Botton, 2017). Pancreas organogenesis in mice starts at embryonic day (E)8.5 when the pancreas anlage is emerging as two independently forming dorsal and ventral buds that later fuse. This process is identified by $P d x 1$ expression, which induces another key TF for pancreas formation, Ptfla (p48) (Burlison et al., 2008; Shih et al., 2013). Two phases of pancreas organogenesis can be distinguished, starting with a primary transition (E8.5-E12.5) to specify pancreatic cell types and a secondary transition (E12.5E17.5) to establish spatial organization of the tissue and cell maturation for generating numerous endocrine and exocrine cells (Bastidas-Ponce et al., 2017; Larsen and Grapin-Botton, 2017; Dumasia and Pethe, 2020). Initiation and maturation depend on an orchestrated network of TF activities.

Analyses of gene expression patterns by in situ hybridization and immunofluorescence labeling revealed that the pancreas is specified by combined activities of Activin, Fgf2, retinoic acid, Bmp, Shh, and Notch pathways. The morphogenetic events involve the underlying mesoderm, endothelium and notochord (Deutsch et al., 2001; Chung et al., 2008; Pan and Wright, 2011; Shih et al., 2013; Xuan and Sussel, 2016; Lorberbaum et al., 2020). Pancreas identity is specified by increasing Pdx1 levels established by a feedback loop induced by Ptfla (Ahlgren et al., 1996; Wiebe et al., 2007). Expression maintenance of these genes is controlled by a network orchestrated by Sox $9, \operatorname{Hnf} 1 \beta$ and Foxa2 (Shih et al., 2013; Bastidas-Ponce et al., 2017). Moreover, Sox9 is important to reinforce pancreatic identity by blocking $C d x 2$ expression combined with activation of the Notch target Hes1, which in turn supports progenitor cell proliferation and repression of the endocrine cell inducer Ngn3 (Figure 1A) (Jensen et al., 2000; Ahnfelt-Rønne et al., 2012; Shih et al., 2015). This network generates a pool of multipotent progenitor cells (MPCs) that expand by combined activation of genes encoding Nkx6.1, Mnx1, 

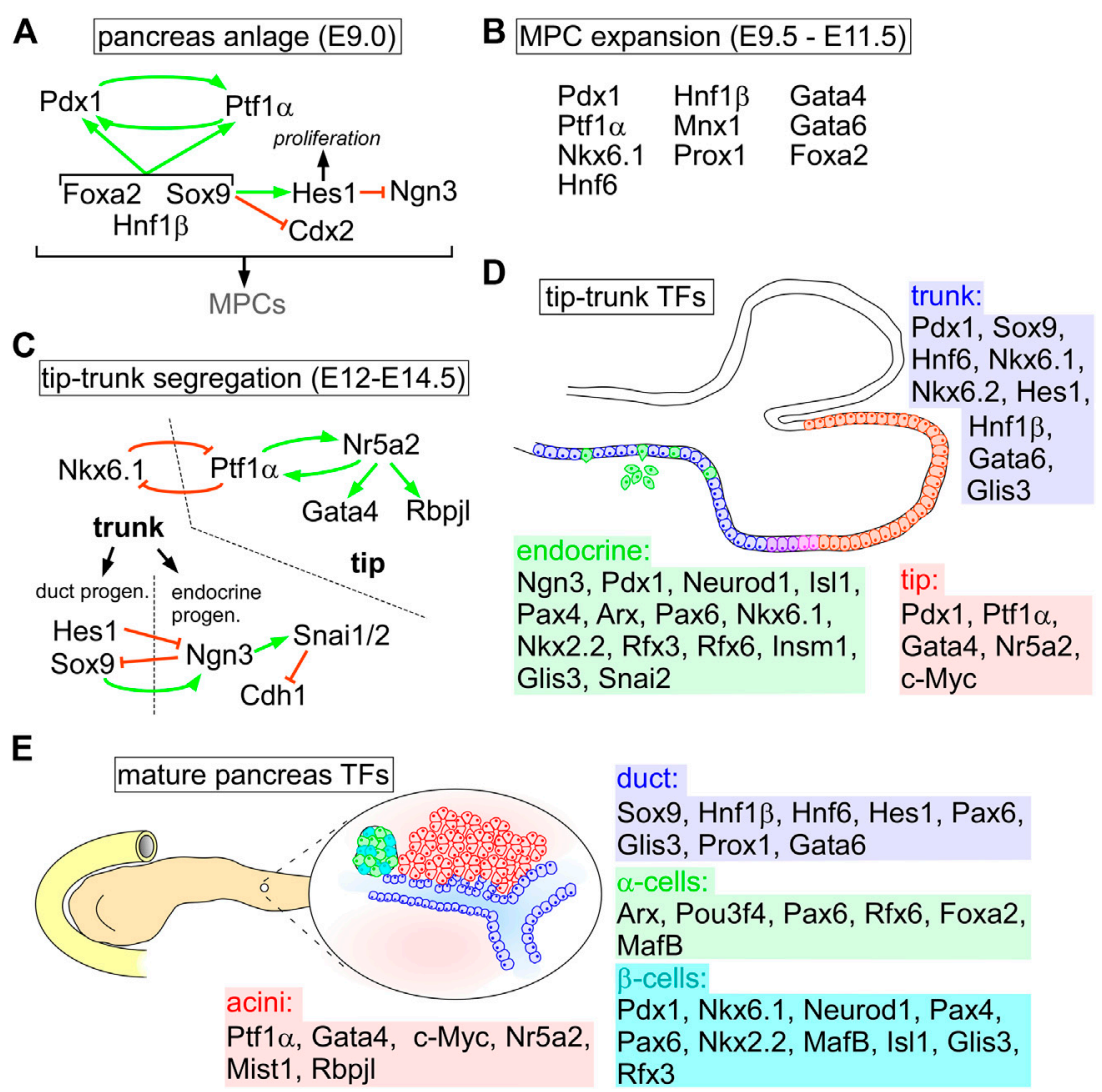

duct:

Sox9, Hnf1及, Hnf6, Hes1, Pax6,

Glis3, Prox1, Gata6

$\alpha$-cells:

Arx, Pou3f4, Pax6, Rfx6, Foxa2

MafB

$\beta$-cells:

Pdx1, Nkx6.1, Neurod1, Pax4,

Pax6, Nkx2.2, MafB, Isl1, Glis3,

Rfx3

FIGURE 1 | Transcription factor networks orchestrating pancreas specification and homeostasis. (A) Early events to form the pancreas anlage and MPC specification. (B) TFs involved in expansion of the MPC pool during primary transition. (C) TF networks to define tip and bipotent trunk domains. In the trunk additional networks are established for endocrine and duct specification. (D) Sketch of tip-trunk cell distribution in the pancreas progenitors highlighting TFs active in each domain's networks. (E) overview on TFs of each cell compartment in the adult pancreas during homeostasis.

Hnf1 $\beta$, Hnf6 (Onecut1), Prox1, Foxa2, and Gata4/6 (Figure 1B) (Gittes, 2009; Pan and Wright, 2011). Many of these TFs have a pivotal role in early pancreas specification, as their loss results in organ agenesis or severe hypoplasia, including Ptf1 $\alpha$, Sox9, Mnx1, Gata4/6, Hnf1 $\beta$, and Hes1 (Jonsson et al., 1994; Offield et al., 1996; Harrison et al., 1999; Li et al., 1999; Jensen et al., 2000; Haumaitre et al., 2005; Seymour et al., 2007, 2012; Watt et al., 2007; Shaw-Smith et al., 2014; Xuan and Sussel, 2016).

Once pancreas identity is established, branching morphogenesis in MPCs leads to separation into tip and trunk cells, precursors of acinar and ductal structures, respectively. Initially co-expressed between E10.5 and E13.5, Nkx6-1 becomes restricted to trunk and Ptfla to tip cells. Tip cells initiate $M y c$ (c-Myc) expression, whereas trunk cells are defined by Hnf1b, Sox9, Hnf6, and Hes1 gene activities (Bastidas-Ponce et al., 2017; Larsen and Grapin-Botton, 2017). Furthermore, expansion and maintenance of the exocrine compartment is further supported by inhibition of the Hippo pathway to repress endocrine specific TF genes, including Pax6, Ngn3, Isl1, and Nkx6-1, as well as Gcg and Ins1/2 (Gao et al., 2013; Dumasia and Pethe, 2020). Consequently, active Hippo signals antagonize Yap activity promoting an endocrine fate (Rosado-
Olivieri et al., 2019). In tip cells, Ptf1 $\alpha$ induces Nr5a2, crucial for acinar identity, as Nr5a2 directly regulates Ptf1a in a feedback loop as well as Gata4 and Rbpjl (Figures 1C,D) (Hale et al., 2014; von Figura et al., 2014). In addition to future acinar and duct cell fates, the endocrine compartment emerges in a few individual cells within the trunk that activate $\mathrm{Ngn3}$, presumably by lateral inhibition orchestrated by the Notch pathway, as shown by lineage tracing in mice ( $\mathrm{Gu}$ et al., 2002; Murtaugh et al., 2003; Magenheim et al., 2011). Ngn $3^{+}$cells delaminate from the trunk epithelium, subsequently cluster and form islets of Langerhans in the proximity of the tubular epithelium (Figure 1D) (Johansson et al., 2007; Pan and Wright, 2011; Shih et al., 2013). This process is reminiscent of epithelial-mesenchymal transition (EMT), by which epithelial cells lose the epithelial identity and apical-basal polarity to gain cell motility (for more details, see Box 1) (Johansson et al., 2007; Pan and Wright, 2011; Shih et al., 2013; Bastidas-Ponce et al., 2017). It involves coordinated expression of Snai1 (Snail) and Snai2 (Slug), EMT-TFs that are directly activated by Ngn3 and repress $C d h 1$ (E-cadherin) (Figures 1C,D) (Rukstalis and Habener, 2007; Gouzi et al., 2011). Interestingly, another EMT-TF, Zeb1, is also expressed at low levels in the epithelial compartment of the developing pancreas. 
BOX 1 | Epithelial-mesenchymal transition.

EMT is an embryonic program that is essential for establishing the three germ-layers and other key morphogenetic events during development, but also becomes activated during wound healing. Besides its physiological function, EMT is hijacked during progression towards metastasis in various cancers (Nieto et al., 2016; Lu and Kang, 2019). The activation of EMT governs changes in cell fate, allowing (partial) transition of stationary epithelial cells towards a motile, invasive mesenchymal state (Johansson et al., 2007; Pan and Wright, 2011; Shih et al., 2013; Bastidas-Ponce et al., 2017). Recent findings show that the process of EMT is highly dynamic, representing a spectrum of intermediary states (Jolly et al., 2015; Nieto et al., 2016; Lambert et al., 2017; Aiello et al., 2018). Moreover, the reverse process mesenchymal-epithelial transition (MET) promotes metastatic colonization and outgrowth, highlighting the need for cellular plasticity during the metastatic cascade (Brabletz, 2012; Takano et al., 2016; Aiello et al., 2018). Various intrinsic and extrinsic signals can mediate the induction of EMT in cancer, often involving the activation of major signaling pathways, including TGF $\beta$, HGF, BMP, PDGF, EGF, SHH, Notch, Integrin, WNT/ $\beta$-catenin, and NF-kB (Taipale and Beachy, 2001; Heldin et al., 2012; Espinoza and Miele, 2013; McCormack and O'Dea, 2013; Gonzalez and Medici, 2014; Mihalko and Brown, 2018; Tam et al., 2020; Xu et al., 2020). Activation of EMT by any of these cascades often converges in the activation of a core set of EMT-TFs, including ZEB1/2, Snail (SNA/1), Slug (SNAl2), and Twist (Nieto et al., 2016; Stemmler et al., 2019). Consequently, EMT-TFs directly or indirectly downregulate genes that promote epithelial identity with apical-basal polarity, including CDH1, EPCAM, Claudins, and miR-200 family members (Brabletz and Brabletz, 2010; Dongre and Weinberg, 2019). Simultaneously, they activate mesenchymal genes that promote migration, invasion, and a front-rear polarity, including CDH2, VIM, ACTA2 (a-SMA), FN1, and MMPs (Dongre and Weinberg, 2019).

In contrast to the role of Snail and Slug during endocrine cell delamination, Zeb1 is crucial for proper lineage specification in correct ratios and for tissue homeostasis in the adult pancreas (Lasierra Losada et al., 2021). Temporal waves of TF expression initiate maturation of endocrine cells to ensure unidirectional unique cell type specification, including Neurod1, Insm1, and Rfx6, whose loss compromises islet cell identity and function (Bastidas-Ponce et al., 2017; Larsen and Grapin-Botton, 2017). Endocrine specification depends on repeated, transient rises in Ngn3 expression in the bipotent progenitor cells, that is regulated by Pax 6 activation, while maintained Pdx1 and Nkx6.1 levels are crucial for $\beta$-cell identity in the mature pancreas (Gannon et al., 2008; Schaffer et al., 2013) (Figure 1D).

In the adult pancreas, mature duct cells are maintained by continuous expression of trunk cell TFs, including Hnf6, Hnf1 $\beta$, Sox9, Hes1, Pax6, Gata6, and Glis3, whereas mature acini express Ptf1a, Gata4, Mist1, and Nr5a2 (Shih et al., 2013; Bastidas-Ponce et al., 2017; Larsen and Grapin-Botton, 2017). Terminally differentiated $\beta$-cells are positive for Pdx1, Nkx6.1, Neurod1, Pax4/6, Rfx3, Nkx2.2, and MafA, whereas $\alpha$-cells are defined by Arx, Pou3f4, Pax6, Rfx6, Foxa2, and MafB expression (Figure 1E) (Gittes, 2009; Pan and Wright, 2011; Shih et al., 2013; Cano et al., 2014; Dassaye et al., 2016; Bastidas-Ponce et al., 2017; Larsen and Grapin-Botton, 2017; Dumasia and Pethe, 2020; Jennings et al., 2020). Besides these regulatory circuits of TFs, correct pancreas progenitor formation, MPC identity, islet specification, and maintenance of individual cell types require epigenetic regulation and the activity of $\mathrm{PcG}$ proteins (Dumasia and Pethe, 2020). Deregulation of the established networks is an inevitable event in tumorigenesis and fosters disease progression.

\section{DEREGULATED EXPRESSION OF TRANSCRIPTION FACTORS IN TUMORIGENESIS}

\subsection{Transcription Factors Driving Pancreatic Ductal Adenocarcinoma Initiation}

PDAC is considered to emerge from a sequential progression of pre-neoplastic precursor lesions. Different histological types of putative precursor lesions have been described: PanIN, intraductal papillary mucinous neoplasia (IPMN), and pancreatic mucinous cystic neoplasm (MCN) (Hruban et al., 2000, 2007). PanIN lesions represent the most extensively studied precursors of PDAC and are categorized from PanIN1 to PanIN3, that accumulate progressive features reflecting increasing dysplastic morphology and acquisition of genetic alterations (Hruban et al., 2000, 2001; Maitra et al., 2003; Hezel et al., 2006; Guerra et al., 2007). Nevertheless, the cell of origin responsible for the initiation and early progression of PDAC remains undetermined. Despite the phenotypic similarity of these benign precursor lesions to ducts, mutant Kras expression in adult mouse ductal cells driven by CK19 failed to induce PDAC, challenging the ductal origin of PDAC (Brembeck et al., 2003; Ray et al., 2011). Data from genetically engineered mouse models (GEMMs) suggest that the expression of oncogenic Kras in acinar cells induces transdifferentiation to duct-like cells during ADM. Although still debated, several lines of evidence suggest that this process precedes the formation of PanIN lesions and ultimately causes PDAC (Carriere et al., 2007; Guerra et al., 2007; Zhu et al., 2007; De La et al., 2008; Habbe et al., 2008; Morris et al., 2010; Kopp et al., 2012; Reichert et al., 2016). For example, analyses of patients with familial pancreatic cancer show that PanIN lesions, as well as ADM, and atypical flat lesions, can be found in human specimens (Brune et al., 2006; Zhu et al., 2007; Shi et al., 2009; Mazur et al., 2010; Aichler et al., 2012; Hidalgo-Sastre et al., 2016). Moreover, besides the classical PanIN-to-PDAC progression model, PDAC initiation was demonstrated to evolve separately from acinar or duct cells in a PanIN-independent mechanism (Ferreira et al., 2017). Likewise, expression of $\mathrm{Kras}^{G 12 D}$ in combination with haploinsufficiency of Smad4 leads to a sequential progression of MCN lesions towards a distinct class of PDAC (Izeradjene et al., 2007). Based on oncogenic mutations, TF networks become deregulated and cells start to transdifferentiate in multiple ways in favor of tumor progression.

Transdifferentiation or loss of cellular identity is a crucial feature at the onset of cancer formation (Slack, 2007; Stanger and Hebrok, 2013; Xiong et al., 2019). Upon injury or inflammation (pancreatitis) in mice, acinar cells can dedifferentiate towards a duct progenitor-like state, transiently expressing acinar, ductal, or early precursor markers to replenish the pancreas during tissue regeneration (Parsa et al., 1985; Song et al., 1999; Miyamoto et al., 
2003; Jensen et al., 2005; Means et al., 2005; Kopp et al., 2012; Stanger and Hebrok, 2013; Storz, 2017). This involves the reexpression of progenitor and lineage-specific TFs and subsequent re-differentiation, demonstrating cellular plasticity induced upon injury. Acinar cell identity in mice is maintained by several cooperating TFs, such as Ptfla and Mist1 (Pin et al., 2001; Rose et al., 2001; Pan and Wright, 2011; Martinelli et al., 2013; Bastidas-Ponce et al., 2017; Larsen and Grapin-Botton, 2017). Downregulation of these TFs results in the acquisition of progenitor cell characteristics and increased ADM and PanIN formation, highlighting the importance of maintained expression of these identity factors to prevent tumor initiation (Miyamoto et al., 2003; De La et al., 2008; Shi et al., 2009; Flandez et al., 2014; von Figura et al., 2014; Krah et al., 2015). In line with that, oncogenic Kras expression prevents the acinar re-differentiation and helps to maintain a ductal phenotype after acute inflammation, e.g. during pancreatitis. This suppressed redifferentiation promotes PanIN progression (Morris et al., 2010; Collins et al., 2012). Furthermore, during the ADM process in PDAC GEMMs, TFs involved in MPC specification or in ductal identity maintenance are (re-)expressed, including Pdx1, Hes1, and Sox9 (Song et al., 1999; Miyamoto et al., 2003; Jensen et al., 2005; Seymour et al., 2007; Kopp et al., 2012). Examples of the role of specific TFs that become deregulated during the early event of transdifferentiation and tumorigenesis are discussed in more detail.

\subsubsection{Gata6}

Initially, Gata6 was presented as an important regulator of early pancreas specification and cell type differentiation, showing a partially overlapping expression with Gata4 (Ketola et al., 2004; Decker et al., 2006). Recently, Gata6 was demonstrated to be required for terminal differentiation and homeostasis of acinar cells and establishment of polarity (Martinelli et al., 2013). Evidently, Gata6 inactivation induces massive loss of acinar cells and fosters ADM in the pancreas (Martinelli et al., 2013). In addition, Gata6 ablation accelerates $\mathrm{Kras}^{\mathrm{G}}{ }^{2 \mathrm{D}}$ driven tumorigenesis, demonstrating that Gata6 maintains acinar differentiation by driving expression of acinar master TFs and suppressing ectopic programs in the pancreas. Hence, in this context, Gata6 functions as a tumor suppressor (Martinelli et al., 2016). In fact, GATA6, among other genes encoding endodermal cell-fate determination TFs, is silenced via promoter hypermethylation in the squamous subtype of PDAC (Bailey et al., 2016; Seino et al., 2018). In line with that, GATA6 expression was preferentially detected in well-differentiated low-grade tumors upon transcription profiling (Collisson et al., 2011; Moffitt et al., 2015; Diaferia et al., 2016). Interestingly, silencing of Gata6 and the subsequent loss of acinar differentiation was observed during nicotine administration in mice, providing a possible link to cigarette smoking, which is a major risk factor contributing to pancreatitis and PDAC initiation (Hermann et al., 2014; Weissman et al., 2020). These findings altogether emphasize the importance of Gata6 maintenance to prevent tumor initiation and progression towards PDAC.

\subsubsection{Mist1}

Mist1 is another acinar specification TF that is crucial for acinar cell maturation, function, stability, and identity and is involved in establishing granule organization and exocytosis pathways (Pin et al., 2001; Johnson et al., 2004; Direnzo et al., 2012). In the absence of Mistl in pancreata with a $\mathrm{Kras}^{\mathrm{G} 12 \mathrm{D}}$ mutation, destabilization of the acinar phenotype leads to acceleration of PanIN formation (Shi et al., 2009). Furthermore, in cell culture models Mist1 was shown to reduce acinar cell proliferation rates by activating p21 (CIP1/WAF1) (Jia et al., 2008). Data from a 3D ADM culture model revealed that forced expression of Mist 1 attenuates $\mathrm{Kras}^{\mathrm{G} 12 \mathrm{D}}$-induced $\mathrm{ADM}$ and PanIN formation (Shi et al., 2013). Activation of Mist1 upon orthotopic transplantation of murine PDAC cells rescues the acinar gene expression program (Jakubison et al., 2018). Overall, the maintenance of a differentiated acinar identity by Mist1 protects acinar cells from early tumorigenesis.

\subsubsection{Ptf1 $\alpha$}

Ptfla maintains acinar cell identity and restrains Kras-mediated tumorigenesis (Rose et al., 2001; Thompson et al., 2012; Krah et al., 2015; Hoang et al., 2016). Nevertheless, Ptf1a is downregulated during inflammation-induced ADM and in acinar cells transformed by Kras ${ }^{\mathrm{G} 12 \mathrm{D}}$ and Notch co-activation (Molero et al., 2007; De La et al., 2008). Specifically, downregulation of Ptfla is a necessary and rate-limiting step in $\mathrm{ADM}$ and neoplastic progression to PanINs and PDAC to overcome the Ptfla-mediated maintenance of acinar gene signatures and quiescence in mice (Krah et al., 2015). Additionally, Ptfla was shown to be epigenetically silenced in murine ADM and PDAC cells harboring an oncogenic Kras allele (Benitz et al., 2016). Moreover, the sustained expression of Ptf1a prevents and reverts Kras-driven pancreas tumorigenesis, rescues the acinar gene program in PDAC cells, and can inhibit tumor growth (Jakubison et al., 2018; Krah et al., 2019). These examples highlight the role of Ptfla as a key transcriptional regulator of acinar cell identity rendering differentiated acinar cells less sensitive for cancer initiation.

\subsubsection{Pdx1}

In the adult pancreas, the primary function of $\operatorname{Pdx} 1$ is the specification and maintenance of mature $\beta$-cells (Ahlgren et al., 1998; Gannon et al., 2008; Gao et al., 2014). During tumor formation, $P d x 1$ is upregulated in $\mathrm{ADM}$ and PanINs upon overexpression of TGFa or expression of oncogenic Kras (Song et al., 1999; Hingorani et al., 2003; Park et al., 2011). In addition, gain- and loss-of-function analyses in human PDAC cell lines resulted in increased proliferation and invasion potential in the presence of PDX1. In contrast, its loss decreases cell survival and tumor growth in vivo, suggesting that PDX1 acts as an oncogene (Liu et al., 2008). In line with that, persistent Pdx1 expression in the normal pancreas promotes ADM induction via Stat3 activation. Simultaneous depletion of Stat3 blocks ADM formation (Miyatsuka et al., 2006). Despite its oncogenic function, $P d x 1$ often becomes downregulated by hypermethylation during progression towards the squamous 
and more aggressive subtype of PDAC. Conversely, PDX1 is part of a transcriptional network determining pancreatic endoderm cell fate and its presence results in a better prognosis in the pancreatic progenitor subtype (Bailey et al., 2016). In line with this conflicting data, Pdxl was demonstrated to act as contextdependent TF during PDAC initiation and progression. Pdx1 switches from a safeguard of acinar cell identity during early tumorigenesis to an oncogene after the establishment of ADM (Roy et al., 2016). In summary, Pdx1 has two opposing functions that are activated in a context- and progression-dependent manner, emphasizing the necessity for more detailed analyses to better understand its bipartite function and prognostic value.

\subsubsection{Sox9}

Expression of Sox9 in the adult pancreas is restricted to cytokeratin-positive duct cells including centroacinar cells (Miyamoto et al., 2003; Seymour et al., 2007; Furuyama et al., 2011; Shroff et al., 2014). During tumor formation, it was shown that Sox9 is induced in ADM and PanINs and is maintained in the pancreatic progenitor PDAC subtype (Morris et al., 2010; Kopp et al., 2012; Prevot et al., 2012; Meng et al., 2014; Grimont et al., 2015). Importantly, ADM and PanINs originating from the acinar compartment require ectopic induction of Sox9. Specific depletion of Sox9 from acinar cells efficiently blocks Kras-mediated PanIN formation in mouse models (Kopp et al., 2012). Furthermore, coexpression of oncogenic Kras and wild-type Sox9 promotes induction of precursor lesions from the acinar compartment (Kopp et al., 2012). Mechanistically, efficient repression of acinar genes and activation of ductal/progenitor genes in cells that undergo ADM is dependent on the combined expression of Sox 9 and Hnf6, as Hnf6 overexpression also triggers ADM in mouse acinar cell lines and upon adenoviral gene delivery in vivo (Prevot et al., 2012). During pancreatitis, inflammation-induced EGFR signaling was shown to induce Nfatc1 and Nfatc4 expression, leading to $\mathrm{ADM}$ and $\mathrm{PDAC}$ progression due to upregulation of Sox9 (Chen et al., 2015; Hessmann et al., 2016). In addition, SOX9 may play a role in the IPMN-PDAC route, however, conflicting evidence have been observed. Some studies identified a gradual decrease in SOX9-positive cells in IPMNs during progression, while others report constant or even elevated SOX9 expression in both low-grade and high-grade IPMNs compared to the normal pancreas (Tanaka et al., 2013; Shroff et al., 2014; Gnerlich et al., 2019). In mice, Arid1a deficiency in the Kras $^{\text {G12D }}$ pancreas results in reduced Sox9 expression and less PanINs, but increased IPMN and PDAC formation. Simultaneous SOX9 overexpression does not affect IPMN incidence, but reduces PDAC formation, demonstrating that Sox9 is a major downstream target of Aridla and prevents tumor progression by promoting ductal differentiation (Kimura et al., 2018). Conclusively, Sox9 is a crucial mediator of ductal- or progenitor-like identity. Due to its embedding in multiple signaling pathways and feedback loops in cell-type specification, its deregulated expression is ultimately linked to early tumorigenesis.

\subsubsection{Hes1}

In the adult pancreas, the expression of the Notch target Hes1 is limited to centroacinar and ductal cells associated with progenitor cell function (Miyamoto et al., 2003; Kopinke et al., 2011). Upregulation of Hes1 by active Notch signaling was observed during ADM and PanIN formation (Hingorani et al., 2003; Miyamoto et al., 2003; Jensen et al., 2005; De La et al., 2008; Plentz et al., 2009). Moreover, Notch-induced Hes1 was suggested to control the expansion of an undifferentiated precursor cell population, thereby promoting Kras-mediated tumor initiation and progression (Miyamoto et al., 2003; Jensen et al., 2005; De La et al., 2008). In fact, acinar-specific expression of mutant Kras induces Hes1 expression along with ADM and PanIN formation. In this context, Notch activation was shown to sensitize acinar cells to mutant Kras-induced ADM/PanIN initiation and progression (De La et al., 2008; Nishikawa et al., 2019). Interestingly, Elastase-mediated Hes1 depletion blocks the progression from ADM to PanINs, combined with a redifferentiation to acinar cells (Nishikawa et al., 2019). However, the role of Hes1 is likely more complex as in another mouse model using Ptfla-mediated Hes 1 ablation and oncogenic Kras induction, loss of Hes 1 displayed increased ADM formation and accelerated PDAC tumorigenesis. Reduced numbers of high-grade PanINs were detected in this model, hinting towards tumor formation from a direct ADM-toPDAC route that skips precancerous PanIN lesions (HidalgoSastre et al., 2016). These findings convey that context-specificity and maintained activity of Notch and Hes1 during homeostasis are essential regulators of tumor initiation.

In summary, PDAC formation depends on early preneoplastic events like ADM, which relies on the downregulation of TFs that control acinar cell identity, including Gata6, Mist1, and Ptfla, and a gain of TFs that promote duct or MPC-like specification, including Pdx1, Sox9, and Hes1 (Figure 2). However, some controversies and the incomplete understanding of the cellular origin of PDAC warrant further analyses to decipher the TF networks that are active during early tumorigenesis.

\subsection{Transcription Factor Alterations Driving Pancreatic Ductal Adenocarcinoma Progression and Metastasis}

Profiling of human PDAC specimens led to the identification of several PDAC subtypes (Collisson et al., 2011; Moffitt et al., 2015; Raphael et al., 2017; Puleo et al., 2018). The classification in the different studies largely overlap with one another (Collisson et al., 2019). Unsupervised clustering of PDAC tumors with high tumor cellularity identified the pancreatic progenitor and squamous subtype, suggesting that only these subtypes define the tumor compartment (Moffitt et al., 2015; Bailey et al., 2016; Puleo et al., 2018). Histopathologic evaluation revealed that tumors belonging to the pancreatic progenitor subtype are moderate-to-well differentiated, whereas the squamous subtype is poorlydifferentiated (Puleo et al., 2018). Transcriptional network analysis of resected human PDAC specimens identified that the pancreatic progenitor subtype is enriched for TF transcripts pivotal for specifying pancreas cell-fate (e.g. PDX1, HNF4A, HNF1B, HNF1A, FOXA2, FOXA3, HES1, and MNX1) (Bailey et al., 2016). The squamous subtypes shows enriched gene 


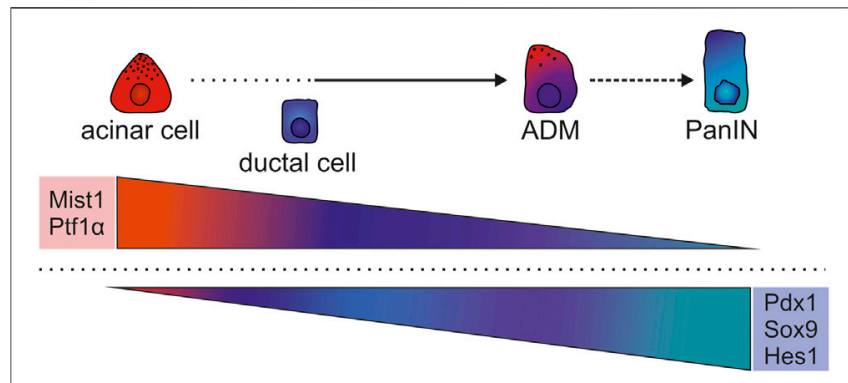

FIGURE 2 | Modulated expression of key TFs of the process of transdifferentiation during ADM. Differentiated acinar cells are specified and maintained by Gata4, Ptf1 a, Mist1, and others, whereas duct cells depend on Sox9, Hes1, and others. During ADM several duct-specific TF networks are induced including Sox9 and Hes1, while acinar-specific networks involving Ptf1 $\alpha$ and Mist1 are collapsing. ADM cells also adopt non-duct like features by activation of $\mathrm{Pdx} 1$, gaining more progenitor-like characteristics. Although Gata6 is required for acinar specification, but absent in mature acinar cells, its continuous expression prevents ADM.

networks involved in TGF $\beta$ signaling, MYC activation, inflammation, metabolic programming, and the upregulation of $\triangle \mathrm{Np} 63$ and its targets. Multi-omics analyses of 24 patientderived xenografts (PDXs) recapitulated the presence of the pancreatic progenitor and squamous subtype (Lomberk et al., 2018). Activated genes in the pancreatic progenitor subtype are mainly involved in pancreas development (e.g. GATA6, BMP2, $P D X 1$, and $S H H$ ) and Ras signaling (e.g. KITLG and RASA3). The squamous subtype shows enrichment for pathways with strong oncogenic potential (e.g. PI3K-AKT, Hippo, and WNT), EMT (e.g. TGF $\beta$ signaling) (Box 1) and deregulation of genes involved in cell proliferation, differentiation and apoptosis (e.g. YAP1, CD44, MYC, and E2F7). These findings connect PDAC subtypes and differentiation states to deregulated signaling pathways. The deregulation of a subset of TFs play a pivotal role in facilitating a subtype switch to the more aggressive squamous phenotype by altering transcriptional regulatory networks. We will discuss these TFs and their effects upon deregulation.

\subsubsection{Subtype-specific Transcription Factors}

The oncogenic KRAS mutation is found in over $90 \%$ of PDAC patients and results in the persistent stimulation of downstream signaling leading to sustained cell proliferation, transformation, migration, and survival (Biankin et al., 2012; Buscail et al., 2020). Although Ras signaling is enriched in the pancreatic progenitor subtype, the activation of certain KRAS downstream mediators is able to foster the transition towards the squamous subtype. Elevation of Etv1, a downstream target of Kras, promotes stromal expansion and metastases through Sparc and Has2 activation in tumors generated by orthotopic transplantation of KPC cells (Kar and Gutierrez-Hartmann, 2013; Heeg et al., 2016). Etv1 overexpression induces all core EMT-TFs (Box 1) and molecular markers associated with the mesenchymal phenotype (e.g. Vim, Mmp3, and Mmp9), whereas knockdown of Etv1 reduces Zeb1 levels. Using human $\mathrm{PaCa}$ cell lines in vitro it was shown that elevation of HAS2 is able to fuel a self-enforcing feedback loop of CD44 and ZEB1 that involves differential splicing of CD44 by ESRP1, further promoting EMT (Preca et al., 2015, 2017). In addition, EMT and enhanced invasion can be activated by increased $M A Z$ expression in human $\mathrm{PaCa}$ cell lines. MAZ acts downstream of KRAS and facilitates CRAFMAPK signaling involving PAK and suppression of $\mathrm{AKT} / \mathrm{PKB}$ (Maity et al., 2018). Moreover, the upregulation of MAPK or inactivation of TP53 leads to the overexpression of KLF7, promoting tumor growth and metastasis in mice (Gupta et al., 2020). Expression of KLF7 activates IFN-stimulated genes and stabilizes Golgi integrity and thus protein glycosylation to enhance the secretion of cancer-promoting growth factors. In cooperation with $M y c$ Yap1 maintains the expression of metabolic genes required for proliferation and survival (Murakami et al., 2019). Ablation of Yap1 in a PDAC mouse model leads to the downregulation of $M y c$, inducing growth arrest and apoptosis (Murakami et al., 2019). Interestingly, a subset of tumor cells was able to restore Myc levels allowing cell survival through the induction of genes encoding EMT-TFs Snail, Zeb2, Twist2, and the stemness factor Sox2, thus compensating for Yap1 loss.

Multiple studies show that the pancreatic progenitor subtype is KRAS-dependent, whereas the squamous subtype is less dependent on KRAS (Singh et al., 2009; Collisson et al., 2011; Ischenko et al., 2021). Moreover, CRISPR/Cas9mediated Kras knockout in tumor cells derived from the KPC mouse model showed pathway enrichment for EMT and TGF $\beta$ signaling, hinting that ablation of Kras drives a subtype switch towards the squamous subtype (Ischenko et al., 2021). Secondary ablation of $\mathrm{Kras}^{\mathrm{G12D}}$ in established tumors of a GEMM with doxycycline-inducible $\mathrm{Kras}^{\text {G12D }}$ and conditional Tp53 inactivation leads to complete regression (Kapoor et al., 2014). Although these initial results are promising, the majority of mice show relapse and exhibit poorly-differentiated pancreatic tumors. The survival of tumor cells in this model in the absence of Kras is mediated by the upregulation of the transcriptional coactivator Yap1, a downstream mediator of the Hippo signaling cascade, and Tead2, forming Yap1/Tead2 complexes coordinating downstream gene expression. Other compensatory mechanisms have been identified, including the induction of the transcriptional repressor Gli2, a downstream mediator of the Shh pathway, upon in vitro Kras ${ }^{\mathrm{G} 12 \mathrm{D}}$ ablation (Adams et al., 2019; Ischenko et al., 2021). Gli2 induction rescued viability and induced upregulation of squamous-specific gene signatures (e.g. Vim and Zeb1). Moreover, GLI2 induction in human $\mathrm{PaCa}$ cell lines promotes a gene signature switch from the pancreatic progenitor towards the squamous subtype, accompanied by a decrease in epithelial identity markers (E-cadherin, ESRP1, GATA6, and SHH) and enrichment in expression of EMT/stemness markers (ZEB1, VIM, CK14, SOX2, and CD44). Primary tumor growth and metastatic outgrowth can be suppressed by ablation of $S P P 1$, a downstream target of GLI2, emphasizing its role in promoting tumor aggressiveness. These findings demonstrate that aberrant activation of several TFs exacerbate PDAC progression (Table 1) with various degrees of KRAS-dependency. Interestingly, these deregulations frequently mediate the indirect upregulation of EMT-TFs (ZEB1/2, Snail, Slug, and Twist) and stemness factors 
TABLE 1 | Overview of the individual TFs and their effects upon elevation in primary PDAC tumors. Influence on cellular identity, subtype, tumor characteristics and biological processes are highlighted. An upward pointing arrow $(\uparrow)$ indicates promoting effects, a downward pointing arrow ( $\downarrow$ ) inhibitory effects, a minus symbol (-) nor promoting nor inhibitory effects. Blank cells reflect that the process was not analyzed or no conclusion could be drawn from the indicated studies.

\begin{tabular}{|c|c|c|c|c|c|c|c|c|c|c|c|c|c|}
\hline \multirow[b]{2}{*}{ TF } & \multirow[b]{2}{*}{ Context } & \multicolumn{2}{|c|}{ Cellular identity } & \multicolumn{2}{|c|}{ Subtype } & \multicolumn{2}{|c|}{ Tumor characteristics } & \multicolumn{5}{|c|}{ Biological processes } & \multirow[b]{2}{*}{ References: } \\
\hline & & Epithelial & Mesenchymal & $\begin{array}{l}\text { Pancreatic } \\
\text { progenitor }\end{array}$ & Squamous & $\begin{array}{l}\text { Growth/ } \\
\text { Progression }\end{array}$ & Metastasis & Proliferation & Stemness & EMT & Invasion & Migration & \\
\hline Yap1 & & & & & $\uparrow$ & $\uparrow$ & & $\uparrow$ & & & & & Kapoor et al. (2014), Lomberk et al. (2018) \\
\hline GLI2 & & $\downarrow$ & $\uparrow$ & $\downarrow$ & $\uparrow$ & & & & $\uparrow$ & $\uparrow$ & & & Adams et al. (2019) \\
\hline ETV1 & & $\downarrow$ & $\uparrow$ & & & $\uparrow$ & $\uparrow$ & - & & $\uparrow$ & $\uparrow$ & & Heeg et al. (2016) \\
\hline MAZ & & $\downarrow$ & $\uparrow$ & & & & & & $\uparrow$ & $\uparrow$ & $\uparrow$ & $\uparrow$ & Maity et al. (2018) \\
\hline KLF7 & & & & & & $\uparrow$ & $\uparrow$ & & & & $\uparrow$ & $\uparrow$ & Gupta et al. (2020) \\
\hline \multirow{2}{*}{ SMAD4 } & $\mathrm{SMAD4}^{+/+}$ & $\downarrow$ & $\uparrow$ & & & $\downarrow$ & & & & $\uparrow$ & & & \multirow{2}{*}{$\begin{array}{l}\text { Bardeesy et al. (2006), Ischenko et al. } \\
\text { (2021) }\end{array}$} \\
\hline & $\mathrm{SMAD}^{-/-}$ & $\uparrow$ & $\downarrow$ & $\uparrow$ & $\downarrow$ & $\uparrow$ & & - & & $\downarrow$ & & & \\
\hline \multirow{2}{*}{ RUNX3 } & $\mathrm{SMAD}^{+/-}$ & & & & & $\uparrow$ & $\downarrow$ & $\uparrow$ & & & $\downarrow$ & $\uparrow$ & \multirow{2}{*}{ Whittle et al. (2015) } \\
\hline & $\mathrm{SMAD}^{-/-}$ & & & & & $\uparrow$ & $\uparrow$ & & & $\downarrow$ & & & \\
\hline TGIF1 & & $\uparrow$ & $\downarrow$ & & & $\downarrow$ & $\downarrow$ & - & $\downarrow$ & $\downarrow$ & $\downarrow$ & $\downarrow$ & Weng et al. (2019) \\
\hline PDX1 & & $\uparrow$ & $\downarrow$ & $\uparrow$ & $\downarrow$ & $\uparrow$ & $\downarrow$ & $\uparrow$ & & $\downarrow$ & $\downarrow$ & & $\begin{array}{l}\text { Collisson et al. (2011), Roy et al. (2016), } \\
\text { Lomberk et al. (2018) }\end{array}$ \\
\hline GATA6 & & $\uparrow$ & $\downarrow$ & $\uparrow$ & $\downarrow$ & $\downarrow$ & $\downarrow$ & $\uparrow$ & & $\downarrow$ & $\downarrow$ & & $\begin{array}{l}\text { (Martinelli et al., 2016, 2017, Lomberk } \\
\text { et al. (2018) }\end{array}$ \\
\hline FOXA1 & & $\uparrow$ & $\downarrow$ & $\uparrow$ & & $\uparrow$ & $\uparrow$ & $\uparrow$ & & $\downarrow$ & $\uparrow$ & $-/ \downarrow$ & $\begin{array}{l}\text { Song et al. (2010), Diaferia et al. (2016), } \\
\text { Martinelli et al. (2017), Roe et al. (2017) }\end{array}$ \\
\hline FOXA2 & & $\uparrow$ & $\downarrow$ & $\uparrow$ & & & & $\uparrow$ & & $\downarrow$ & & $\downarrow$ & $\begin{array}{l}\text { Song et al. (2010), Bailey et al. (2016), } \\
\text { Martinelli et al. (2017) }\end{array}$ \\
\hline $\mathrm{HNF} 4 a$ & & $\uparrow$ & $\downarrow$ & $\uparrow$ & $\downarrow$ & $\downarrow$ & - & $\downarrow$ & & & & & Bailey et al. (2016), Camolotto et al. (2021) \\
\hline \multirow[t]{2}{*}{ HNF1a } & & & & & & & & $\downarrow$ & & & & & Hoskins et al. (2014), Luo et al. (2015) \\
\hline & & & & & $\downarrow$ & $\uparrow$ & & $\uparrow$ & $\uparrow$ & & $\uparrow$ & $\uparrow$ & Abel et al. (2018), Subramani et al. (2020) \\
\hline SIX1 & & & & - & - & $\uparrow$ & & $\uparrow$ & & & & & \multirow{2}{*}{ Camolotto et al. (2021) } \\
\hline SIX4 & & & & $\downarrow$ & $\uparrow$ & $\uparrow$ & & $\uparrow$ & & & & & \\
\hline $\mathrm{BACH} 1$ & & $\downarrow$ & $\uparrow$ & & & - & $\uparrow$ & - & & $\uparrow$ & $\uparrow$ & $\uparrow$ & Sato et al. (2020) \\
\hline ZEB1 & & $\downarrow$ & $\uparrow$ & $\downarrow$ & $\uparrow$ & - & $\uparrow$ & $\uparrow$ & $\uparrow$ & $\uparrow$ & $\uparrow$ & & Krebs et al. (2017) \\
\hline SNAI2 & & $\downarrow$ & $\uparrow$ & & $\uparrow$ & $\uparrow$ & $\uparrow$ & & & $\uparrow$ & $\uparrow$ & $\uparrow$ & Recouvreux et al. (2020) \\
\hline SOX2 & & $\downarrow$ & - & & & & & $\uparrow$ & $\uparrow$ & $\uparrow$ & & & Herreros-Villanueva et al. (2013) \\
\hline PRRX1A & & $\uparrow$ & $\downarrow$ & $\uparrow$ & $\downarrow$ & & $\uparrow$ & $\uparrow$ & & $\downarrow$ & $\downarrow$ & & \multirow[t]{2}{*}{ Takano et al. (2016) } \\
\hline PRRX1B & & $\uparrow$ & $\downarrow$ & $\downarrow$ & $\downarrow$ & & $\uparrow$ & & & $\uparrow$ & $\uparrow$ & & \\
\hline
\end{tabular}




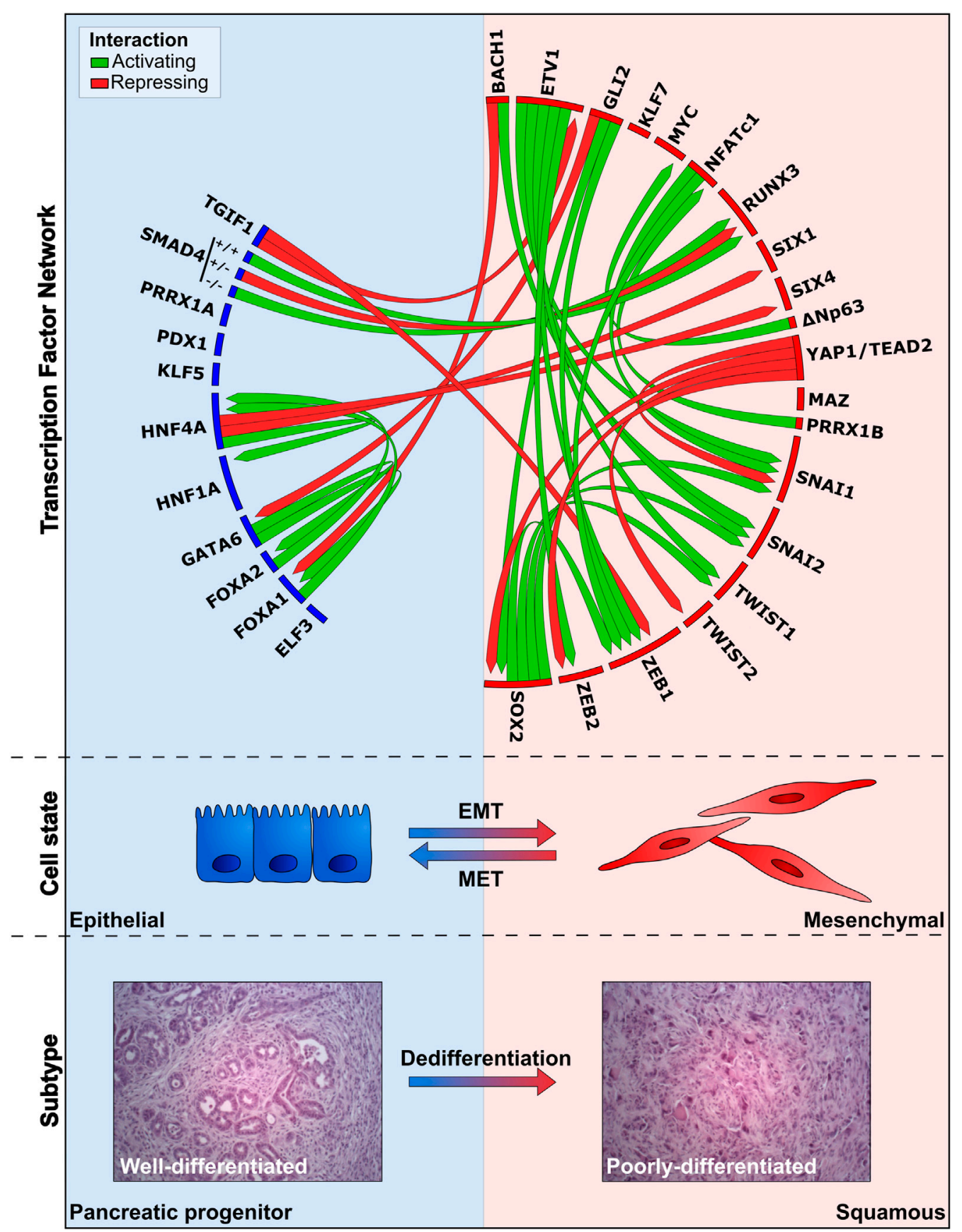

FIGURE 3 | Overview of TF networks active during PaCa progression, EMT, and metastasis. The deregulation directly or indirectly affects the expression of other TFs, thereby promoting or inhibiting the differentiation/EMT state. TFs depicted in the blue box are associated with the epithelial cell-state/pancreatic progenitor subtype (E-PP), whereas the red box shows TFs linked to the mesenchymal-state/squamous subtype (M-S). Links resulting in activation and repression of TFs in the network are indicated by green and red lines, respectively. Expression of E-PP TFs in the blue box promote the differentiated endoderm/epithelial identity, block dedifferentiation, and prevent activation of stemness/EMT/dedifferentiation TFs. Activation of M-S TFs is associated with a mesenchymal identity, promotes dedifferentiation and activation of EMT and stemness. TFs without connections in the network have been associated with specific subtypes, but how they integrate into the network is poorly understood. H\&E images depict well-differentiated and poorly-differentiated tumors, derived from KPC primary pancreatic tumors, reflecting E-PP and M-S phenotypes (adapted from Krebs et al. (2017)).

(SOX2 and CD44) (Figure 3, Box 1). These findings corroborate that the induction of the reversible EMT program promotes an aggressive PDAC phenotype by enabling cellular plasticity, metastasis formation, chemoresistance, and the acquisition of CSC properties in PDAC (Satoh et al., 2015; Wang et al., 2015; Zheng et al., 2015; Krebs et al., 2017; Aiello et al., 2018; Recouvreux et al., 2020). 
Apart from the activation of signaling cascades downstream of KRAS driving the subtype transition, the squamous subtype shows enrichment for TGF $\beta$ signaling (Bailey et al., 2016; Lomberk et al., 2018). In pre-malignant cells TGF $\beta$ acts as a tumor suppressor by inducing cell-cycle arrest, differentiation, and apoptosis (Massagué, 2008). Disruption of TGF $\beta$ signaling in PDAC prevents the tumor-suppressive effects, while activation of TGF $\beta$ signaling in a progressed state is a potent inducer of EMT (Dardare et al., 2020). A central player in canonical TGF $\beta$ signaling is SMAD4, whose inactivation or loss occurs as a late event during PDAC progression (Wilentz et al., 2000). The role of Smad4 in progression and metastasis remains controversial, as Smad4-deficiency attenuates EMT, leads to upregulated E-cadherin protein levels, and promotes a welldifferentiated PDAC phenotype in the $\operatorname{Kras}^{G 12 D}$;Ink4a/Arf mouse model (Bardeesy et al., 2006; Ahmed et al., 2017; Shichi et al., 2019). Moreover, simultaneous knockout of Smad4 and Kras reduces EMT-related genes and promotes a Ras signaling signature (Ischenko et al., 2021). In contrast, other studies show that the loss of SMAD4 is associated with shorter overall survival and a squamous phenotype (Blackford et al., 2009; Yamada et al., 2015). Interestingly, the TF Runx3 promotes metastatic colonization but is dependent on the Smad4 state (Whittle et al., 2015). Heterozygous Smad4 inactivation in the KPC mouse model promotes progression and growth of the primary tumor, while loss of the remaining wild-type allele leads to a highly metastatic disease. Furthermore, the expression of TGF $\beta$ target genes can be repressed by elevated TGIF1, potentially decreasing PDAC progression as demonstrated by HEK-293 cell transfection experiments and in PDAC mice (Seo et al., 2004; Weng et al., 2019). In summary, the intricate balance among several TFs involved in TGF $\beta$ signaling and their mutational status determine the impact on progression.

On the other hand, several endodermal lineage specifiers promote the pancreatic progenitor molecular subtype in PDAC, such as GATA6, FOXA1/A2, and HNF4a, identified in silico (Bailey et al., 2016; Roe et al., 2017; Brunton et al., 2020). Although PDX1 expression is often increased during ADM and tumor onset, its downregulation or loss is mainly observed in poorly-differentiated tumors correlated with EMT and metastasis (Roy et al., 2016). Hence, high expression of PDX1 is observed in the pancreatic progenitor subtype and well-differentiated tumors (Ischenko et al., 2014; Roy et al., 2016; Lomberk et al., 2018). Dysregulation of these TFs by inactivating mutations or repression can affect the EMT-equilibrium towards a more squamous identity. As an example, loss of Gata6 in a mouse PDAC model decreases the $C d h 1$ inducers Foxa1/a2 and derepresses EGFR signaling in favor of dedifferentiation (Martinelli et al., 2016, 2017). In contrast, FOXA1 elevation was identified in patients' primary lesions and well-differentiated low-grade tumors, in part by activating HNF4A and other endodermal lineage specifiers (Duncan et al., 1998; Diaferia et al., 2016; Roe et al., 2017). Together with Gata6, Foxa1/a2 block EMT and promote epithelial differentiation in GEMM PDAC models (Song et al., 2010; Martinelli et al., 2017). Hence, direct transcriptional repression of FOXA1 by $\mathrm{BACH} 1$ is required for metastatic colonization of AsPC-1 PaCa cells in an orthotopic implantation model (Sato et al., 2020). Interestingly, loss of FOXA1/A2 is frequently detected in the squamous subtype and is sufficient to induce EMT in human PaCa cell lines (Song et al., 2010; Roe et al., 2017). Apart from repressing FOXA1, BACH1 activates SNAI2, which further promotes EMT, assessed by gene inactivation in human cell lines (Sato et al., 2020). Transcriptomic analysis on primary tumors and patient-derived cell lines revealed that during tumorigenesis HNF4a directly activates $H N F 1 A$, and loss of the former enables a transition towards a more squamous phenotype (Brunton et al., 2020; Camolotto et al., 2021). Moreover, HNF4a directly represses the mesodermal and neural differentiation TFs SIX1/4, whose elevated expression was linked to the squamous subtype (Camolotto et al., 2021). Downregulation of $H N F 1 A$ is observed in the tumor vs. normal pancreas, suggesting that decreased HNF1a levels are important for PDAC tumor progression (Hoskins et al., 2014; Luo et al., 2015). Overexpression of $H N F 1 A$ decreases cell-doubling times, while its knockdown significantly increases proliferation in vitro. HNF1a downregulates apoptosis inhibitors and modulates the expression of cell cycle genes. However, whether HNF1a acts through the AKT/mTOR pathway requires additional investigation, since silencing of $H N F 1 A$ activates AKT/mTOR signaling, but may also result in reduced expression of PI3K, AKT and mTOR (Hoskins et al., 2014; Luo et al., 2015; Subramani et al., 2020). Other studies indicate that HNF1A is an oncogene necessary for the regulation of cancer stem cell (CSC) populations in PDAC, promotes anchorage-independent growth, proliferation, as well as invasive and migratory capacities (Abel et al., 2018; Subramani et al., 2020). These contradictory findings could be explained by the hypothesis that cellular plasticity and thus the ability to induce partial-EMT is indeed necessary to acquire stemness, whereas reversal to an epithelial phenotype is crucial for metastatic outgrowth at secondary sites. Conclusively, the expression of several TFs involved in specifying pancreatic cell-fate maintain the pancreatic progenitor subtype by (in)directly promoting epithelial-identity markers and inhibiting EMT/dedifferentiation (Table 1). Their downregulation abrogates these effects, allowing a switch towards the more aggressive squamous subtype (Figure 3).

\subsubsection{Induction of Epithelial-Mesenchymal Transition and Metastasis}

Comparisons between primary PDAC tumors and matched metastasis revealed no specific metastasis-inducing genetic mutations, hinting towards gene regulatory mechanisms affecting late PDAC progression and metastasis (Campbell et al., 2010; Yachida et al., 2010; Makohon-Moore et al., 2017). The involvement of EMT-TFs in PDAC invasion and metastasis was initially questioned due to experimental challenges to observe EMT and the metastatic cascade in vivo. In particular, depletion of either Twist or Snail in the KPC mouse model of PDAC is not affecting metastasis formation, indicating that they are dispensable for this process (Zheng et al., 2015). However, depletion of Zeb1 in the same mouse model suppresses metastasis formation as well as experimental lung colonization capacity, stemness, and cell and metabolic plasticity (Krebs et al., 
BOX 2 | Epigenetic regulation of gene expression.

Epigenetic mechanisms control the accessibility for TFs and the transcription machinery to selective regions of the genome. Consequently, depending on the state of the epigenetic landscape, TFs can bind to cis-regulatory elements to regulate gene transcription (Shen and Laird, 2013; Klemm et al., 2019). These mechanisms can be broadly divided into: post-translational histone modifications, DNA/RNA modifications (e.g. methylation) and non-coding RNAs (Shen and Laird, 2013; Lu et al., 2020). Histone modifications at specific regulatory regions include methylation and acetylation predominantly at histone $\mathrm{H} 3$ sites $\mathrm{K} 4$, $\mathrm{K} 9$, and $\mathrm{K} 27$ and are associated with active genes/promoters (H3K4me3), active/poised enhancers (H3K4me1), polycomb-repressed regions (H3K27me3) or heterochromatin (H3K9me3). These post-translational marks are set by a group of histone modifications enzymes, which are reviewed elsewhere (Bannister and Kouzarides, 2011). Super-enhancers (SEs) are a special type of enhancer which have been first identified in embryonic stem cells with clusters of TF binding sites for Sox2, Oct4 and Nanog (Hnisz et al., 2013 ; Whyte et al., 2013). SEs have also been identified in cancer and represent large regions of chromatin (up to $20 \mathrm{~kb}$ ) that are densely clustered with enhancers, highly enriched for TF binding sites (Hnisz et al., 2013; Whyte et al., 2013). Their function is crucial in shaping cellular identity by regulating cell-type specific gene expression in both normal and diseased states (Hnisz et al., 2013).

2017). Moreover, glutamine depletion promotes metastasis of orthotopically and intravenously injected KPC cells through induction of EMT by upregulation of Snai2 via ERK signaling and ATF4 activation (Recouvreux et al., 2020). Collectively, these findings and research on core EMT-TFs in other cancers show that their individual contribution to invasion and metastasis is highly dependent on the cellular context (Elloul et al., 2005; Imamichi et al., 2007; Caramel et al., 2013; Denecker et al., 2014; Fischer et al., 2015; Zheng et al., 2015; Krebs et al., 2017; Stemmler et al., 2019; Recouvreux et al., 2020).

Liver metastases in KPC mouse models show elevated expression of Foxal and Prrxla, whereas the expression of these factors decreases when the primary tumor acquires more squamous-associated features during progression (Takano et al., 2016; Roe et al., 2017). The decrease during progression and elevated expression in liver metastases suggests that re-expression of TFs associated with the pancreatic progenitor subtype is essential for successful liver colonization. Moreover, it was shown that Prrxla enhances self-renewal, decreases invasiveness, and promotes metastatic outgrowth (Takano et al., 2016). Isoform b, on the other hand, fosters invasion, EMT, and dedifferentiation by promoting $\mathrm{Hgf}$ expression, suggesting that both isoforms distinctively regulate EMT and MET to form overt metastases. In addition, these two isoforms can form homo- and heterodimers, affecting transcriptional activity in human PaCa cell lines (Marchand et al., 2019). Simultaneous inactivation of Snail and Twist induces a shift of the EMT-equilibrium to a more epithelial-like state in the primary tumor of KPC mice while enhancing liver metastases (Carstens et al., 2021). Scal and Pdx1 levels are also regulating metastatic capacities: Sca ${ }^{-}$cell lines derived from the KPC mouse model express elevated levels of Pdx1 and successfully metastasize in lungs and lymph nodes upon tail vein injections, whereas Sca ${ }^{+}$ cells with lower levels of Pdx1 fail to metastasize (Ischenko et al., 2014). These findings support the idea that the reinforcement of epithelial features and thus cellular plasticity are required for metastatic competence (Figure 3).

\subsection{Chromatin Dynamics and Epigenetic Regulation of Pancreatic Ductal Adenocarcinoma}

In addition to the deregulation of established TF networks in tumor progression, epigenetic mechanisms of gene regulation are altered and become hijacked by cancer cells resulting in global changes in gene expression (Box 2). Genomic analyses in human PDAC revealed that up to $10 \%$ of mutations are identified in chromatin remodeling genes (Hayashi et al., 2021). Moreover, the epigenetic landscape of PDXs revealed that the squamous and pancreatic progenitor subtype can also be classified by patterns in DNA methylation and gene regulatory elements (Nicolle et al., 2017; Lomberk et al., 2018). Deregulation of specific histone modification enzymes in PDAC can lead to the transition towards the more aggressive squamous subtype by altering the chromatin states. Specifically, mutations in histone lysine demethylase 6a (KDM6A) combined with p53 alterations were associated with the squamous subtype of PDAC (Bailey et al., 2016). Loss of $K D M 6 A$ alone is sufficient to induce a squamous-like subtype through activation of $\triangle \mathrm{Np} 63$ (TP63), MYC, and RUNX3 enhancer regions (Andricovich et al., 2018). Interestingly, upregulation of $\triangle \mathrm{Np} 63$ alone is able to reprogram the enhancer landscape towards the squamous subtype by installing $\mathrm{H} 3 \mathrm{~K} 27 \mathrm{ac}$ near genes promoting this subtype (Somerville et al., 2018). Upregulation of the histone methyltransferase $N s d 2$ increases the global accumulation of the activation mark $\mathrm{H} 3 \mathrm{~K} 36 \mathrm{me}$, thereby enriching the squamous gene signature in the KPC model. In contrast, loss of $\mathrm{Nsd} 2$ decreases $\mathrm{H} 3 \mathrm{~K} 36 \mathrm{me} 2$, resulting in enrichment of markers of the pancreatic progenitor subtype (Yuan et al., 2020). These findings suggest that the accumulation of dimethylation at H3K36 is necessary for cells to undergo EMT. Moreover, H3K36me2 may induce alterations in the enhancer landscape as its decrease leads to loss of $\mathrm{H} 3 \mathrm{~K} 27 \mathrm{ac}$ in the same domains. Interestingly $\mathrm{H} 3 \mathrm{~K} 36 \mathrm{me} 2$ transcriptionally affects the enhancer activity and thus the expression of most EMT-TF genes (Zeb1/2, Snail, and Twist2) and of other metastasis-promoting TFs (Yuan et al., 2020). Histone methyltransferase EZH2 is part of the polycomb repressor complex 2 (PRC2) to set $\mathrm{H} 3 \mathrm{~K} 27$ methylation marks (Viré et al., 2006; Völkel et al., 2015). During pancreas regeneration, EZH2 transcriptionally represses NFATC1, whereas during tumorigenesis it induces NFATC1 to drive KRAS-mediated PaCa plasticity (Chen et al., 2017). Making use of uncoupling Ezh2-NFATc1 regulation by combining conditional Nfatc1 activation with Ezh2 inactivation in Kras ${ }^{G 12 D}$ mice, Patil et al. recently showed that partial loss of Ezh2 leads to more differentiated PDAC tumors and fewer liver metastases in line with higher EZH2 protein expression in human high-grade tumors (Patil et al., 2021). Strikingly the most abundant negatively regulated target of Ezh2 is Gata6, a key regulator of endodermal identity. Moreover, re-expression of 
wild-type Ezh2 abrogates Gata6 expression in Ezh2-deficient cells. Conclusively, alterations in histone modification enzymes affect the chromatin states and aid in PDAC progression by inducing or repressing genes involved in PDAC progression.

Very recently, a strong contribution to PDAC progression was observed by the regulation of so-called super-enhancers (SEs) (Box 2) (Andricovich et al., 2018; Lomberk et al., 2018; Somerville et al., 2018). Comparisons between healthy cells and related cancer cells revealed that these SEs accumulate close to the loci of oncogenes during cancer progression, thus playing an important role in tumorigenesis (Hnisz et al., 2013). Profiling of the SE landscape revealed that several TFs transcriptionally regulate the expression of genes associated with the pancreatic progenitor subtype by binding upstream of these SEs (i.e. GATA6, FOS, FOXP1, FOXP4, KLF4, ELF3, NFIX, CUX1, and SSBP3) (Lomberk et al., 2018). These SEs mainly regulate genes of TFs associated with pancreas development (including HNF1A, $H N F 4 A$, and $P D X 1)$ and lipid metabolism. Epigenomic mapping of PDXs and $\mathrm{PaCa}$ cell lines showed that $\triangle \mathrm{Np} 63$ activates squamous-specific SEs, including those near FAT2, NECTIN1, and HIF1A loci (Hamdan and Johnsen, 2018). Depletion of $\triangle \mathrm{Np} 63$ reduces the $\mathrm{H} 3 \mathrm{~K} 27 \mathrm{ac}$ at those SEs, indicating the dependency of $\Delta \mathrm{Np} 63$ for writing these $\mathrm{H} 3 \mathrm{~K} 27$ acetylation marks. Loss of KLF5 leads to a reduction in $\mathrm{H} 3 \mathrm{~K} 27 \mathrm{ac}$ and H3K4me1 near these (super-)enhancers, inducing activation of stem cell- and mesenchymal-associated genes (Diaferia et al., 2016). KLF5 was shown to be selectively expressed in welldifferentiated human PDAC tumors and is required to maintain the expression of epithelial identity genes. Moreover, binding of KLF5 to enhancers increased the binding of ELF3 and FOXA1, which are both associated with low-grade PDAC tumors, demonstrating how KLF5 contributes to the regulation of pancreatic progenitor identity (Diaferia et al., 2016).

Progressive loss of repressive marks in large heterochromatin domains (H3K9 and H4K20) and increased H3K9, H3K27, and $\mathrm{H} 4 \mathrm{~K} 16 \mathrm{ac}$ were found in distant metastases in comparison to the primary tumor, which helped to follow the acquisition of malignant traits (McDonald et al., 2017). These traits included resistance to oxidative stress, promoting a poorly-differentiated state, upregulation of DNA repair genes, and downregulation of oncogenic signal transduction in distant lung metastases. Comparisons of the epigenetic landscape from matched tumor and metastasis-derived organoids of the KPC model revealed that metastatic transition is accompanied by prominent changes in H3K27 acetylation, predominantly in enhancer regions. These changes are controlled by Foxa1, which is upregulated in metastases and was shown to cooperate with Gata5 for enhancer activation (Roe et al., 2017). Epigenetic regulation is also required to overcome the tumor-suppressive effects of TGF $\beta$ signaling, i.e., the induced senescence and apoptosis before it can act as a trigger of EMT induction. Strikingly, NFATc1 elevation is crucial to overcome TGF $\beta$-induced growth arrest by antagonizing $\mathrm{H} 3 \mathrm{~K} 27 \mathrm{ac}$ and activation of TGF $\beta$ target genes including Birc5, Ccnd1, and Plk1 (Hasselluhn et al., 2019).

Altogether, these findings indicate that epigenetic states define the molecular subtypes of PDAC in a highly dynamic process. Alterations in the epigenetic landscape including SEs are key features in PDAC progression towards malignancy, supporting the acquisition of cellular plasticity.

\section{NOVEL THERAPEUTIC APPROACHES TO TARGET TRANSCRIPTION FACTORS}

Despite the advances in therapies, non-metastatic local PDAC eligible for surgical resection followed by adjuvant chemotherapy remains the sole curative option, applicable for only $10-20 \%$ of patients (Gillen et al., 2010; Werner et al., 2013; Benassai et al., 2015; Orth et al., 2019). First-line treatment options for patients with locally advanced or distant metastatic PDAC are usually limited to conventional chemotherapies. Despite changes in treatment regimens from monotherapies to multi-agent chemotherapies, the survival rates of $\mathrm{PaCa}$ patients remain largely unchanged and success is severely limited due to de novo acquisition or pre-existing resistance. Various intrinsic and extrinsic tumor feature alterations have been proposed contributing to drug resistance, including the microenvironment, altered metabolism, EMT, and the presence of CSCs (Grasso et al., 2017; Swayden et al., 2018; Tuerhong et al., 2021). The lack of blood vessels and the abundant desmoplasia create a hypoxic and nutrient-scarce environment, forcing PDAC cells to alter their metabolism to sustain proliferation (Sousa and Kimmelman, 2014; Yang et al., 2020). In addition, these microenvironmental features impede therapeutic delivery (Neesse et al., 2011; Dufort et al., 2016). In general, global efforts are made to design precision therapies to combat PDAC, including therapeutic targets to inhibit tumorintrinsic pathways such as KRAS, PI3K, AKT, mTOR, JAK/ STAT, SHH, NOTCH, and WNT signaling cascades (Chandana et al., 2019). These strategies predominantly target mediators in oncogenic signaling cascades upstream of TFs, thereby indirectly affecting the expression of deregulated TFs. So far, the only precision medicine approved for PDAC treatment is erlotinib, a potent inhibitor of EGFR-related kinase, used in combination with gemcitabine (Moore et al., 2007; Sinn et al., 2017).

As summarized before, PDAC is highly plastic, and inhibition of certain kinases can be compensated by the dysregulation of other effectors (as seen for KRAS) and often converge to the same set of TFs (e.g. ZEB1/2, Snail, Slug, Twist, and SOX2) (Figure 3). Hence, these TFs are attractive therapeutic targets. For example, silencing of ZEB1 restores the expression of epithelial markers and resensitizes $\mathrm{PaCa}$ cells to standard chemotherapy (Arumugam et al., 2009; Wellner et al., 2009; Meidhof et al., 2015). Similarly, treatment with the HDAC inhibitor Mocetinistat in vitro and upon xenotransplantation upregulates ZEB1-repressed target genes, particularly miR-200 and miR-203, reducing ZEB1 protein expression and restoring drug sensitivity (Meidhof et al., 2015). Moreover, knockout of Snail or Twist increased the sensitivity to erlotinib and gemcitabine (Zheng et al., 2015). Although initially thought to be undruggable, recent attempts to design and identify drugs that target TFs are promising (Henley and Koehler, 2021). Strategies to inhibit TFs directly and indirectly include targeting the 
expression level, modulating proteasomal degradation, disrupting protein/protein interactions, and ligand/DNA binding abilities (Lambert et al., 2018; Bushweller, 2019).

Multiple clinical trials are currently ongoing to evaluate therapeutics that indirectly target $\mathrm{TF}$ expression levels in PDAC. Studies on triptolide (TPL), a diterpenoid triepoxide, shows promising results in PDAC cell lines and orthotopic pancreatic cancer models (Borja-Cacho et al., 2010; Chugh et al., 2012; Zhao et al., 2020). TPL binds to XPB, a subunit of TFIIH, thereby inhibiting transcription globally (Vispé et al., 2009; Titov et al., 2011). Moreover, treatment with TPL (Minnelide) leads to a rapid downregulation of MYC gene expression and protein levels (Titov et al., 2011). Phase II clinical trials are currently ongoing to study the effect of TPL on non-responsive PDAC tumors. In addition, clinical attempts to target epigenetic deregulation are currently under evaluation. These include treatment with Azitidine and/or Romideposin, in combination with immuno- as well as standard chemotherapeutic treatments in patients with surgically resected and advanced PDAC. The inhibition of effectors upstream of TFs may pose severe problems in non-neoplastic cells, as these pathways are often indispensable for proper cell functioning. It is hypothesized that direct TF-targeting approaches minimize the side effects by precisely modulating their deregulated transcriptional programs (Henley and Koehler, 2021). The drug COTI-2, a thiosemicarbazone, has been shown to directly convert mutant p53 to the wild-type 3D structure. TP53 is approximately mutated in $72 \%$ of all PDAC (Raphael et al., 2017). Gain-of-function mutations in TP53 increase the aggressiveness in $\mathrm{PaCa}$ and promotes metastasis (Morton et al., 2010; Weissmueller et al., 2014). Additionally, it negatively regulates the PI3K/AKT/mTOR pathway (Salim et al., 2016; Robertson et al., 2020). Phase I clinical trials are currently ongoing to study the effect of COTI-2 as monotherapy or with combinations for

\section{REFERENCES}

Abel, E. V., Goto, M., Magnuson, B., Abraham, S., Ramanathan, N., Hotaling, E., et al. (2018). HNF1A Is a Novel Oncogene that Regulates Human Pancreatic Cancer Stem Cell Properties. Elife 7, e33947. doi:10.7554/elife.33947

Adams, C. R., Htwe, H. H., Marsh, T., Wang, A. L., Montoya, M. L., Subbaraj, L., et al. (2019). Transcriptional Control of Subtype Switching Ensures Adaptation and Growth of Pancreatic Cancer. Elife 8, e45313. doi:10.7554/elife.45313

Ahlgren, U., Jonsson, J., and Edlund, H. (1996). The Morphogenesis of the Pancreatic Mesenchyme Is Uncoupled from that of the Pancreatic Epithelium in IPF1/PDX1-Deficient Mice. Development 122, 1409-1416. doi:10.1242/dev.122.5.1409

Ahlgren, U., Jonsson, J., Jonsson, L., Simu, K., and Edlund, H. (1998). Beta -cellspecific Inactivation of the Mouse Ipf1/Pdx1 Gene Results in Loss of the Beta -cell Phenotype and Maturity Onset Diabetes. Genes Develop. 12, 1763-1768. doi:10.1101/gad.12.12.1763

Ahmed, S., Bradshaw, A.-D., Gera, S., Dewan, M., and Xu, R. (2017). The TGF$\beta /$ Smad4 Signaling Pathway in Pancreatic Carcinogenesis and its Clinical Significance. Jcm 6, 5. doi:10.3390/jcm6010005

Ahnfelt-Rønne, J., Jørgensen, M. C., Klinck, R., Jensen, J. N., Füchtbauer, E.-M., Deering, T., et al. (2012). Ptfla-mediated Control of Dll1 Reveals an Alternative to the Lateral Inhibition Mechanism. Development 139, 33-45. doi:10.1242/ dev.071761 the treatment of malignancies. Moreover, bi-weekly treatment of pretreated metastatic PDAC patients with the STAT3 inhibitor BBI608, shows promising activity (Bekaii-Saab et al., 2016).

The advent of targeted therapies to target TF together with the advances in other therapeutic strategies (e.g. immunotherapy, targeting receptors, membrane transporters, and enzymes) and rise of precision medicine bear the promise to improve PDAC patient outcomes. Although the field is still evolving, these combinational treatments offer valuable options for $\mathrm{PaCa}$ patients to overcome acquired therapy resistance and aggressive phenotypes.

\section{AUTHOR CONTRIBUTIONS}

All authors listed have made a substantial, direct, and intellectual contribution to the work and approved it for publication.

\section{FUNDING}

This work was supported by the German Research Foundation (TRR305 TP A03, B01 and B07, FOR2438 P04 and BR1399/9-1, BR1399/10-1, BR4145/1-1 and BR4145/2-1) and the European Union's Horizon 2020 research and innovation program under the Marie Skłodowska-Curie grant agreement (No. 861196; PRECODE).

\section{ACKNOWLEDGMENTS}

We apologize to our colleagues whose work could not be cited owing to space limitations. The transcriptional interaction network was constructed using circlize v. 0.4 (Gu et al., 2014).

Aichler, M., Seiler, C., Tost, M., Siveke, J., Mazur, P. K., Da Silva-Buttkus, P., et al. (2012). Origin of Pancreatic Ductal Adenocarcinoma from Atypical Flat Lesions: a Comparative Study in Transgenic Mice and Human Tissues. J. Pathol. 226, 723-734. doi:10.1002/path.3017

Aiello, N. M., Maddipati, R., Norgard, R. J., Balli, D., Li, J., Yuan, S., et al. (2018). EMT Subtype Influences Epithelial Plasticity and Mode of Cell Migration. Develop. Cel 45, 681-695. e4. doi:10.1016/j.devcel.2018.05.027

Andricovich, J., Perkail, S., Kai, Y., Casasanta, N., Peng, W., and Tzatsos, A. (2018). Loss of KDM6A Activates Super-enhancers to Induce Gender-specific Squamous-like Pancreatic Cancer and Confers Sensitivity to BET Inhibitors. Cancer Cell 33, 512-526. e8. doi:10.1016/j.ccell.2018.02.003

Arumugam, T., Ramachandran, V., Fournier, K. F., Wang, H., Marquis, L., Abbruzzese, J. L., et al. (2009). Epithelial to Mesenchymal Transition Contributes to Drug Resistance in Pancreatic Cancer. Cancer Res. 69, 5820-5828. doi:10.1158/0008-5472.can-08-2819

Atkinson, M. A., Campbell-Thompson, M., Kusmartseva, I., and Kaestner, K. H. (2020). Organisation of the Human Pancreas in Health and in Diabetes. Diabetologia 63, 1966-1973. doi:10.1007/s00125-020-05203-7

Bailey, P., Chang, D. K., Nones, K., Johns, A. L., Patch, A. M., Gingras, M. C., et al. (2016). Genomic Analyses Identify Molecular Subtypes of Pancreatic Cancer. Nature 531, 47-52. doi:10.1038/nature16965

Bannister, A. J., and Kouzarides, T. (2011). Regulation of Chromatin by Histone Modifications. Cell Res 21, 381-395. doi:10.1038/cr.2011.22

Bardeesy, N., Cheng, K.-h., Berger, J. H., Chu, G. C., Pahler, J., Olson, P., et al. (2006). Smad4 Is Dispensable for normal Pancreas Development yet Critical in 
Progression and Tumor Biology of Pancreas Cancer. Genes Develop. 20, 3130-3146. doi:10.1101/gad.1478706

Bastidas-Ponce, A., Scheibner, K., Lickert, H., and Bakhti, M. (2017). Cellular and Molecular Mechanisms Coordinating Pancreas Development. Development 144, 2873-2888. doi:10.1242/dev.140756

Bekaii-Saab, T. S., Mikhail, S., Langleben, A., Becerra, C., Jonker, D. J., Asmis, T. R., et al. (2016). A Phase Ib/II Study of BBI608 Combined with Weekly Paclitaxel in Advanced Pancreatic Cancer. Jco 34, 196. doi:10.1200/jco.2016.34.4_suppl.196

Benassai, G., Quarto, G., Perrotta, S., Furino, E., Benassai, G. L., Amato, B., et al. (2015). Long-term Survival after Curative Resection for Pancreatic Ductal Adenocarcinoma - Surgical Treatment. Int. J. Surg. 21, S1-S3. doi:10.1016/ j.ijsu.2015.06.050

Benitz, S., Regel, I., Reinhard, T., Popp, A., Schäffer, I., Raulefs, S., et al. (2016). Polycomb Repressor Complex 1 Promotes Gene Silencing through H2AK119 Mono-Ubiquitination in Acinar-To-Ductal Metaplasia and Pancreatic Cancer Cells. Oncotarget 7, 11424-11433. doi:10.18632/ oncotarget.6717

Biankin, A. V., Waddell, N., Kassahn, K. S., Gingras, M. C., Muthuswamy, L. B., Johns, A. L., et al. (2012). Pancreatic Cancer Genomes Reveal Aberrations in Axon Guidance Pathway Genes. Nature 491, 399-405. doi:10.1038/ nature11547

Blackford, A., Serrano, O. K., Wolfgang, C. L., Parmigiani, G., Jones, S., Zhang, X., et al. (2009). SMAD4 Gene Mutations Are Associated with Poor Prognosis in Pancreatic Cancer. Clin. Cancer Res. 15, 4674-4679. doi:10.1158/10780432.ccr-09-0227

Borja-Cacho, D., Yokoyama, Y., Chugh, R. K., Mujumdar, N. R., Dudeja, V., Clawson, K. A., et al. (2010). TRAIL and Triptolide: An Effective Combination that Induces Apoptosis in Pancreatic Cancer Cells. J. Gastrointest. Surg. 14, 252-260. doi:10.1007/s11605-009-1065-6

Brabletz, S., and Brabletz, T. (2010). The ZEB/miR-200 Feedback Loop-A Motor of Cellular Plasticity in Development and Cancer. EMBO Rep. 11, 670-677. doi:10.1038/embor.2010.117

Brabletz, T. (2012). EMT and MET in Metastasis: Where Are the Cancer Stem Cells. Cancer Cell 22, 699-701. doi:10.1016/j.ccr.2012.11.009

Brembeck, F. H., Schreiber, F. S., Deramaudt, T. B., Craig, L., Rhoades, B., Swain, G., et al. (2003). The Mutant K-Ras Oncogene Causes Pancreatic Periductal Lymphocytic Infiltration and Gastric Mucous Neck Cell Hyperplasia in Transgenic Mice. Cancer Res. 63, 2005-2009.

Brune, K., Abe, T., Canto, M., O'Malley, L., Klein, A. P., Maitra, A., et al. (2006). Multifocal Neoplastic Precursor Lesions Associated with Lobular Atrophy of the Pancreas in Patients Having a strong Family History of Pancreatic Cancer. Am. J. Surg. Pathol. 30, 1067-1076.

Brunton, H., Caligiuri, G., Cunningham, R., Upstill-Goddard, R., Bailey, U. M., Garner, I. M., et al. (2020). HNF4A and GATA6 Loss Reveals Therapeutically Actionable Subtypes in Pancreatic Cancer. Cell Rep 31, 107625. doi:10.1016/ j.celrep.2020.107625

Burlison, J. S., Long, Q., Fujitani, Y., Wright, C. V. E., and Magnuson, M. A. (2008). Pdx-1 and Ptfla Concurrently Determine Fate Specification of Pancreatic Multipotent Progenitor Cells. Develop. Biol. 316, 74-86. doi:10.1016/ j.ydbio.2008.01.011

Buscail, L., Bournet, B., and Cordelier, P. (2020). Role of Oncogenic KRAS in the Diagnosis, Prognosis and Treatment of Pancreatic Cancer. Nat. Rev. Gastroenterol. Hepatol. 17, 153-168. doi:10.1038/s41575-019-0245-4

Bushweller, J. H. (2019). Targeting Transcription Factors in Cancer - from Undruggable to Reality. Nat. Rev. Cancer 19, 611-624. doi:10.1038/s41568019-0196-7

Camolotto, S. A., Belova, V. K., Torre-Healy, L., Vahrenkamp, J. M., Berrett, K. C., Conway, H., et al. (2021). Reciprocal Regulation of Pancreatic Ductal Adenocarcinoma Growth and Molecular Subtype by HNF4a and SIX1/4. Gut 70, 900-914. doi:10.1136/gutjnl-2020-321316

Campbell, P. J., Yachida, S., Mudie, L. J., Stephens, P. J., Pleasance, E. D., Stebbings, L. A., et al. (2010). The Patterns and Dynamics of Genomic Instability in Metastatic Pancreatic Cancer. Nature 467, 1109-1113. doi:10.1038/ nature 09460

Cano, D. A., Soria, B., Martín, F., and Rojas, A. (2014). Transcriptional Control of Mammalian Pancreas Organogenesis. Cell. Mol. Life Sci. 71, 2383-2402. doi:10.1007/s00018-013-1510-2
Caramel, J., Papadogeorgakis, E., Hill, L., Browne, G. J., Richard, G., Wierinckx, A., et al. (2013). A Switch in the Expression of Embryonic EMT-Inducers Drives the Development of Malignant Melanoma. Cancer Cell 24, 466-480. doi:10.1016/j.ccr.2013.08.018

Carriere, C., Seeley, E. S., Goetze, T., Longnecker, D. S., and Korc, M. (2007). The Nestin Progenitor Lineage Is the Compartment of Origin for Pancreatic Intraepithelial Neoplasia. Proc. Natl. Acad. Sci. 104, 4437-4442. doi:10.1073/ pnas.0701117104

Carstens, J. L., Yang, S., Correa de Sampaio, P., Zheng, X., Barua, S., McAndrews, K. M., et al. (2021). Stabilized Epithelial Phenotype of Cancer Cells in Primary Tumors Leads to Increased Colonization of Liver Metastasis in Pancreatic Cancer. Cel Rep. 35, 108990. doi:10.1016/j.celrep.2021.108990

Chan-Seng-Yue, M., Kim, J. C., Wilson, G. W., Ng, K., Figueroa, E. F., O’Kane, G. M., et al. (2020). Transcription Phenotypes of Pancreatic Cancer Are Driven by Genomic Events during Tumor Evolution. Nat. Genet. 52, 231-240. doi:10.1038/s41588-019-0566-9

Chandana, S., Babiker, H. M., and Mahadevan, D. (2019). Therapeutic Trends in Pancreatic Ductal Adenocarcinoma (PDAC). Expert Opin. Investig. Drugs 28, 161-177. doi:10.1080/13543784.2019.1557145

Chen, N.-M., Neesse, A., Dyck, M. L., Steuber, B., Koenig, A. O., LubesederMartellato, C., et al. (2017). Context-Dependent Epigenetic Regulation of Nuclear Factor of Activated $\mathrm{T}$ Cells 1 in Pancreatic Plasticity. Gastroenterology 152, 1507-1520. e15. doi:10.1053/j.gastro.2017.01.043

Chen, N.-M., Singh, G., Koenig, A., Liou, G.-Y., Storz, P., Zhang, J.-S., et al. (2015). NFATc1 Links EGFR Signaling to Induction of Sox9 Transcription and AcinarDuctal Transdifferentiation in the Pancreas. Gastroenterology 148, 1024-1034. e9. doi:10.1053/j.gastro.2015.01.033

Chugh, R., Sangwan, V., Patil, S. P., Dudeja, V., Dawra, R. K., Banerjee, S., et al. (2012). A Preclinical Evaluation of Minnelide as a Therapeutic Agent against Pancreatic Cancer. Sci. Transl. Med. 4, 156ra139. doi:10.1126/ scitranslmed.3004334

Chung, W.-S., Shin, C. H., and Stainier, D. Y. R. (2008). Bmp2 Signaling Regulates the Hepatic versus Pancreatic Fate Decision. Develop. Cel 15, 738-748. doi:10.1016/j.devcel.2008.08.019

Collins, M. A., Bednar, F., Zhang, Y., Brisset, J.-C., Galbán, S., Galbán, C. J., et al. (2012). Oncogenic Kras Is Required for Both the Initiation and Maintenance of Pancreatic Cancer in Mice. J. Clin. Invest. 122, 639-653. doi:10.1172/JCI59227

Collisson, E. A., Bailey, P., Chang, D. K., and Biankin, A. V. (2019). Molecular Subtypes of Pancreatic Cancer. Nat. Rev. Gastroenterol. Hepatol. 16, 207-220. doi:10.1038/s41575-019-0109-y

Collisson, E. A., Sadanandam, A., Olson, P., Gibb, W. J., Truitt, M., Gu, S., et al. (2011). Subtypes of Pancreatic Ductal Adenocarcinoma and Their Differing Responses to Therapy. Nat. Med. 17, 500-503. doi:10.1038/nm.2344

Dardare, J., Witz, A., Merlin, J.-L., Gilson, P., and Harlé, A. (2020). SMAD4 and the TGF $\beta$ Pathway in Patients with Pancreatic Ductal Adenocarcinoma. Ijms 21, 3534. doi:10.3390/ijms21103534

Dassaye, R., Naidoo, S., and Cerf, M. E. (2016). Transcription Factor Regulation of Pancreatic Organogenesis, Differentiation and Maturation. Islets 8, 13-34. doi:10.1080/19382014.2015.1075687

De La O, J.-P., Emerson, L. L., Goodman, J. L., Froebe, S. C., Illum, B. E., Curtis, A. B., et al. (2008). Notch and Kras Reprogram Pancreatic Acinar Cells to Ductal Intraepithelial Neoplasia. Proc. Natl. Acad. Sci. 105, 18907-18912. doi:10.1073/ pnas.0810111105

Decker, K., Goldman, D. C., Grasch, C. L., and Sussel, L. (2006). Gata6 Is an Important Regulator of Mouse Pancreas Development. Develop. Biol. 298, 415-429. doi:10.1016/j.ydbio.2006.06.046

Denecker, G., Vandamme, N., Akay, Ö., Koludrovic, D., Taminau, J., Lemeire, K., et al. (2014). Identification of a ZEB2-MITF-ZEB1 Transcriptional Network that Controls Melanogenesis and Melanoma Progression. Cell Death Differ 21, 1250-1261. doi:10.1038/cdd.2014.44

Deutsch, G., Jung, J., Zheng, M., Lóra, J., and Zaret, K. S. (2001). A Bipotential Precursor Population for Pancreas and Liver within the Embryonic Endoderm. Development 128, 871-881. doi:10.1242/dev.128.6.871

Diaferia, G. R., Balestrieri, C., Prosperini, E., Nicoli, P., Spaggiari, P., Zerbi, A., et al. (2016). Dissection of Transcriptional and Cis -regulatory Control of Differentiation in Human Pancreatic Cancer. EMBO J. 35, 595-617. doi:10.15252/embj.201592404 
Direnzo, D., Hess, D. A., Damsz, B., Hallett, J. E., Marshall, B., Goswami, C., et al. (2012). Induced Mist1 Expression Promotes Remodeling of Mouse Pancreatic Acinar Cells. Gastroenterology 143, 469-480. doi:10.1053/j.gastro.2012.04.011

Dongre, A., and Weinberg, R. A. (2019). New Insights into the Mechanisms of Epithelial-Mesenchymal Transition and Implications for Cancer. Nat. Rev. Mol. Cel. Biol. 20, 69-84. doi:10.1038/s41580-018-0080-4

Dufort, C. C., Delgiorno, K. E., and Hingorani, S. R. (2016). Mounting Pressure in the Microenvironment: Fluids, Solids, and Cells in Pancreatic Ductal Adenocarcinoma. Gastroenterology 150, 1545-1557. e2. doi:10.1053/ j.gastro.2016.03.040

Dumasia, N. P., and Pethe, P. S. (2020). Pancreas Development and the Polycomb Group Protein Complexes. Mech. Develop. 164, 103647. doi:10.1016/ j.mod.2020.103647

Duncan, S. A., Navas, M. A., Dufort, D., Rossant, J., and Stoffel, M. (1998). Regulation of a Transcription Factor Network Required for Differentiation and Metabolism. Science 281, 692-695. doi:10.1126/science.281.5377.692

Elloul, S., Bukholt Elstrand, M., Nesland, J. M., Tropé, C. G., Kvalheim, G., Goldberg, I., et al. (2005). Snail, Slug, and Smad-Interacting Protein 1 as Novel Parameters of Disease Aggressiveness in Metastatic Ovarian and Breast Carcinoma. Cancer 103, 1631-1643. doi:10.1002/cncr.20946

Espinoza, I., and Miele, L. (2013). Deadly Crosstalk: Notch Signaling at the Intersection of EMT and Cancer Stem Cells. Cancer Lett. 341, 41-45. doi:10.1016/j.canlet.2013.08.027

European Comission (2020). Estimates of Cancer Incidence and Mortality in 2020, for All Cancer Sites. ECIS - Eur. Cancer Inf. Syst.

Ferlay, J., Partensky, C., and Bray, F. (2016). More Deaths from Pancreatic Cancer Than Breast Cancer in the EU by 2017. Acta Oncologica 55, 1158-1160. doi:10.1080/0284186X.2016.1197419

Ferreira, R. M. M., Sancho, R., Messal, H. A., Nye, E., Spencer-Dene, B., Stone, R. K., et al. (2017). Duct- and Acinar-Derived Pancreatic Ductal Adenocarcinomas Show Distinct Tumor Progression and Marker Expression. Cel. Rep. 21, 966-978. doi:10.1016/j.celrep.2017.09.093

Fischer, K. R., Durrans, A., Lee, S., Sheng, J., Li, F., Wong, S. T. C., et al. (2015). Epithelial-to-mesenchymal Transition Is Not Required for Lung Metastasis but Contributes to Chemoresistance. Nature 527, 472-476. doi:10.1038/ nature 15748

Flandez, M., Cendrowski, J., Cañamero, M., Salas, A., del Pozo, N., Schoonjans, K., et al. (2014). Nr5a2heterozygosity Sensitises to, and Cooperates with, Inflammation inKRasG12V-Driven Pancreatic Tumourigenesis. Gut 63, 647-655. doi:10.1136/gutjnl-2012-304381

Furney, S. J., Higgins, D. G., Ouzounis, C. A., and López-Bigas, N. (2006). Structural and Functional Properties of Genes Involved in Human Cancer. BMC Genomics 7, 3. doi:10.1186/1471-2164-7-3

Furuyama, K., Kawaguchi, Y., Akiyama, H., Horiguchi, M., Kodama, S., Kuhara, T., et al. (2011). Continuous Cell Supply from a Sox9-Expressing Progenitor Zone in Adult Liver, Exocrine Pancreas and Intestine. Nat. Genet. 43, 34-41. doi:10.1038/ng.722

Gannon, M., Tweedie Ables, E., Crawford, L., Lowe, D., Offield, M. F., Magnuson, M. A., et al. (2008). pdx-1 Function Is Specifically Required in Embryonic $\beta$ Cells to Generate Appropriate Numbers of Endocrine Cell Types and Maintain Glucose Homeostasis. Develop. Biol. 314, 406-417. doi:10.1016/ j.ydbio.2007.10.038

Gao, T., McKenna, B., Li, C., Reichert, M., Nguyen, J., Singh, T., et al. (2014). Pdx1 Maintains $\beta$ Cell Identity and Function by Repressing an a Cell Program. Cel. Metab. 19, 259-271. doi:10.1016/j.cmet.2013.12.002

Gao, T., Zhou, D., Yang, C., Singh, T., Penzo-Méndez, A., Maddipati, R., et al. (2013). Hippo Signaling Regulates Differentiation and Maintenance in the Exocrine Pancreas. Gastroenterology 144, 1543-1553. e1. doi:10.1053/ j.gastro.2013.02.037

Gillen, S., Schuster, T., Meyer zum Büschenfelde, C., Friess, H., and Kleeff, J. (2010). Preoperative/neoadjuvant Therapy in Pancreatic Cancer: A Systematic Review and Meta-Analysis of Response and Resection Percentages. Plos Med. 7, e1000267. doi:10.1371/journal.pmed.1000267

Gittes, G. K. (2009). Developmental Biology of the Pancreas: a Comprehensive Review. Develop. Biol. 326, 4-35. doi:10.1016/j.ydbio.2008.10.024

Gnerlich, J. L., Ding, X., Joyce, C., Turner, K., Johnson, C. D., Chen, H., et al. (2019). Increased SOX9 Expression in Premalignant and Malignant Pancreatic Neoplasms. Ann. Surg. Oncol. 26, 628-634. doi:10.1245/s10434-018-6925-4
Goggins, M., Hruban, R. H., and Kern, S. E. (2000). BRCA2 Is Inactivated Late in the Development of Pancreatic Intraepithelial Neoplasia. Am. J. Pathol. 156, 1767-1771. doi:10.1016/S0002-9440(10)65047-X

Gonzalez, D. M., and Medici, D. (2014). Signaling Mechanisms of the EpithelialMesenchymal Transition. Sci. Signal. 7, re8. doi:10.1126/scisignal.2005189

Gouzi, M., Kim, Y. H., Katsumoto, K., Johansson, K., and Grapin-Botton, A. (2011). Neurogenin3 Initiates Stepwise Delamination of Differentiating Endocrine Cells during Pancreas Development. Dev. Dyn. 240, 589-604. doi:10.1002/dvdy.22544

Grasso, C., Jansen, G., and Giovannetti, E. (2017). Drug Resistance in Pancreatic Cancer: Impact of Altered Energy Metabolism. Crit. Rev. Oncology/Hematology 114, 139-152. doi:10.1016/j.critrevonc.2017.03.026

Grimont, A., Pinho, A. V., Cowley, M. J., Augereau, C., Mawson, A., GiryLaterrière, M., et al. (2015). SOX9 Regulates ERBB Signalling in Pancreatic Cancer Development. Gut 64, 1790-1799. doi:10.1136/gutjnl-2014-307075

Gu, G., Dubauskaite, J., and Melton, D. A. (2002). Direct Evidence for the Pancreatic Lineage: NGN3+ Cells Are Islet Progenitors and Are Distinct from Duct Progenitors. Development 129, 2447-2457. doi:10.1242/ dev.129.10.2447

Gu, Z., Gu, L., Eils, R., Schlesner, M., and Brors, B. (2014). Circlize Implements and Enhances Circular Visualization in R. Bioinformatics 30, 2811-2812. doi:10.1093/bioinformatics/btu393

Guerra, C., Schuhmacher, A. J., Cañamero, M., Grippo, P. J., Verdaguer, L., PérezGallego, L., et al. (2007). Chronic Pancreatitis Is Essential for Induction of Pancreatic Ductal Adenocarcinoma by K-Ras Oncogenes in Adult Mice. Cancer Cell 11, 291-302. doi:10.1016/j.ccr.2007.01.012

Gupta, R., Malvi, P., Parajuli, K. R., Janostiak, R., Bugide, S., Cai, G., et al. (2020). KLF7 Promotes Pancreatic Cancer Growth and Metastasis by Up-Regulating ISG Expression and Maintaining Golgi Complex Integrity. Proc. Natl. Acad. Sci. USA 117, 12341-12351. doi:10.1073/pnas.2005156117

Habbe, N., Shi, G., Meguid, R. A., Fendrich, V., Esni, F., Chen, H., et al. (2008). Spontaneous Induction of Murine Pancreatic Intraepithelial Neoplasia (mPanIN) by Acinar Cell Targeting of Oncogenic Kras in Adult Mice. Proc. Natl. Acad. Sci. 105, 18913-18918. doi:10.1073/ pnas.0810097105

Hale, M. A., Swift, G. H., Hoang, C. Q., Deering, T. G., Masui, T., Lee, Y.-K., et al. (2014). The Nuclear Hormone Receptor Family Member NR5A2 Controls Aspects of Multipotent Progenitor Cell Formation and Acinar Differentiation during Pancreatic Organogenesis. Development 141, 3123-3133. doi:10.1242/ dev.109405

Hamdan, F. H., and Johnsen, S. A. (2018). DeltaNp63-dependent Super Enhancers Define Molecular Identity in Pancreatic Cancer by an Interconnected Transcription Factor Network. Proc. Natl. Acad. Sci. USA 115, E12343-E12352. doi:10.1073/pnas.1812915116

Hanahan, D., and Weinberg, R. A. (2011). Hallmarks of Cancer: the Next Generation. Cell 144, 646-674. doi:10.1016/j.cell.2011.02.013

Hanahan, D., and Weinberg, R. A. (2000). The Hallmarks of Cancer. Cell 100, 57-70. doi:10.1016/j.cell.2011.02.01310.1016/s0092-8674(00)81683-9

Harrison, K. A., Thaler, J., Pfaff, S. L., Gu, H., and Kehrl, J. H. (1999). Pancreas Dorsal Lobe Agenesis and Abnormal Islets of Langerhans in Hlxb9-Deficient Mice. Nat. Genet. 23, 71-75. doi:10.1038/12674

Hasselluhn, M. C., Schmidt, G. E., Ellenrieder, V., Johnsen, S. A., and Hessmann, E. (2019). Aberrant NFATc1 Signaling Counteracts TGF $\beta$-Mediated Growth Arrest and Apoptosis Induction in Pancreatic Cancer Progression. Cell Death Dis. 10, 446. doi:10.1038/s41419-019-1682-2

Haumaitre, C., Barbacci, E., Jenny, M., Ott, M. O., Gradwohl, G., and Cereghini, S. (2005). Lack of TCF2/vHNF1 in Mice Leads to Pancreas Agenesis. Proc. Natl. Acad. Sci. 102, 1490-1495. doi:10.1073/pnas.0405776102

Hayashi, A., Hong, J., and Iacobuzio-Donahue, C. A. (2021). The Pancreatic Cancer Genome Revisited. Nat. Rev. Gastroenterol. Hepatol. 18, 469-481. doi:10.1038/s41575-021-00463-Z

Heeg, S., Das, K. K., Reichert, M., Bakir, B., Takano, S., Caspers, J., et al. (2016). ETS-transcription Factor ETV1 Regulates Stromal Expansion and Metastasis in Pancreatic Cancer. Gastroenterology 151, 540-553. e14. doi:10.1053/ j.gastro.2016.06.005

Heldin, C.-H., Vanlandewijck, M., and Moustakas, A. (2012). Regulation of EMT by TGF $\beta$ in Cancer. FEBS Lett. 586, 1959-1970. doi:10.1016/ j.febslet.2012.02.037 
Henley, M. J., and Koehler, A. N. (2021). Advances in Targeting 'undruggable' Transcription Factors with Small Molecules. Nat. Rev. Drug Discov. 20, 669-688. doi:10.1038/s41573-021-00199-0

Hermann, P. C., Sancho, P., Cañamero, M., Martinelli, P., Madriles, F., Michl, P., et al. (2014). Nicotine Promotes Initiation and Progression of KRAS-Induced Pancreatic Cancer via Gata6-dependent Dedifferentiation of Acinar Cells in Mice. Gastroenterology 147, 1119-1133. e4. doi:10.1053/j.gastro.2014.08.002

Herreros-Villanueva, M., Zhang, J.-S., Koenig, A., Abel, E. V., Smyrk, T. C., Bamlet, W. R., et al. (2013). SOX2 Promotes Dedifferentiation and Imparts Stem Celllike Features to Pancreatic Cancer Cells. Oncogenesis 2, e61. doi:10.1038/ oncsis. 2013.23

Hessmann, E., Zhang, J.-S., Chen, N.-M., Hasselluhn, M., Liou, G.-Y., Storz, P., et al. (2016). NFATc4 RegulatesSox9Gene Expression in Acinar Cell Plasticity and Pancreatic Cancer Initiation. Stem Cell Int. 2016, 1-11. doi:10.1155/2016/ 5272498

Hezel, A. F., Kimmelman, A. C., Stanger, B. Z., Bardeesy, N., and Depinho, R. A. (2006). Genetics and Biology of Pancreatic Ductal Adenocarcinoma. Genes Develop. 20, 1218-1249. doi:10.1101/gad.1415606

Hidalgo-Sastre, A., Brodylo, R. L., Lubeseder-Martellato, C., Sipos, B., Steiger, K., Lee, M., et al. (2016). Hesl Controls Exocrine Cell Plasticity and Restricts Development of Pancreatic Ductal Adenocarcinoma in a Mouse Model. Am. J. Pathol. 186, 2934-2944. doi:10.1016/j.ajpath.2016.07.025

Hingorani, S. R., Petricoin, E. F., Maitra, A., Rajapakse, V., King, C., Jacobetz, M. A., et al. (2003). Preinvasive and Invasive Ductal Pancreatic Cancer and its Early Detection in the Mouse. Cancer Cell 4, 437-450. doi:10.1016/s1535-6108(03) 00309-x

Hnisz, D., Abraham, B. J., Lee, T. I., Lau, A., Saint-André, V., Sigova, A. A., et al. (2013). Super-enhancers in the Control of Cell Identity and Disease. Cell 155, 934-947. doi:10.1016/j.cell.2013.09.053

Hoang, C. Q., Hale, M. A., Azevedo-Pouly, A. C., Elsässer, H. P., Deering, T. G., Willet, S. G., et al. (2016). Transcriptional Maintenance of Pancreatic Acinar Identity, Differentiation, and Homeostasis by PTF1A. Mol. Cel. Biol. 36, 3033-3047. doi:10.1128/mcb.00358-16

Hoskins, J. W., Jia, J., Flandez, M., Parikh, H., Xiao, W., Collins, I., et al. (2014). Transcriptome Analysis of Pancreatic Cancer Reveals a Tumor Suppressor Function for HNF1A. Carcinogenesis 35, 2670-2678. doi:10.1093/carcin/ bgu193

Hruban, R. H., Goggins, M., Parsons, J., and Kern, S. E. (2000). Progression Model for Pancreatic Cancer. Clin. Cancer Res. 6, 2969-2972.

Hruban, R. H., Adsay, N. V., Albores-Saavedra, J., Compton, C., Garrett, E. S., Goodman, S. N., et al. (2001). Pancreatic Intraepithelial Neoplasia. Am. J. Surg. Pathol. 25, 579-586. doi:10.1097/00000478-200105000-00003

Hruban, R. H., Maitra, A., Kern, S. E., and Goggins, M. (2007). Precursors to Pancreatic Cancer. Gastroenterol. Clin. North America 36, 831-849. doi:10.1016/j.gtc.2007.08.012

Imamichi, Y., König, A., Gress, T., and Menke, A. (2007). Collagen Type I-Induced Smad-Interacting Protein 1 Expression Downregulates E-Cadherin in Pancreatic Cancer. Oncogene 26, 2381-2385. doi:10.1038/sj.onc.1210012

Ischenko, I., D’Amico, S., Rao, M., Li, J., Hayman, M. J., Powers, S., et al. (2021). KRAS Drives Immune Evasion in a Genetic Model of Pancreatic Cancer. Nat. Commun. 12, 1482. doi:10.1038/s41467-021-21736-w

Ischenko, I., Petrenko, O., and Hayman, M. J. (2014). Analysis of the TumorInitiating and Metastatic Capacity of PDX1-Positive Cells from the Adult Pancreas. Proc. Natl. Acad. Sci. USA 111, 3466-3471. doi:10.1073/ pnas.1319911111

Izeradjene, K., Combs, C., Best, M., Gopinathan, A., Wagner, A., Grady, W. M., et al. (2007). KrasG12D and Smad4/Dpc4 Haploinsufficiency Cooperate to Induce Mucinous Cystic Neoplasms and Invasive Adenocarcinoma of the Pancreas. Cancer Cell 11, 229-243. doi:10.1016/j.ccr.2007.01.017

Jakubison, B. L., Schweickert, P. G., Moser, S. E., Yang, Y., Gao, H., Scully, K., et al. (2018). Induced PTF 1a Expression in Pancreatic Ductal Adenocarcinoma Cells Activates Acinar Gene Networks, Reduces Tumorigenic Properties, and Sensitizes Cells to Gemcitabine Treatment. Mol. Oncol. 12, 1104-1124. doi:10.1002/1878-0261.12314

Jennings, R. E., Scharfmann, R., and Staels, W. (2020). Transcription Factors that Shape the Mammalian Pancreas. Diabetologia 63, 1974-1980. doi:10.1007/ s00125-020-05161-0
Jensen, J. N., Cameron, E., Garay, M. V. R., Starkey, T. W., Gianani, R., and Jensen, J. (2005). Recapitulation of Elements of Embryonic Development in Adult Mouse Pancreatic Regeneration. Gastroenterology 128, 728-741. doi:10.1053/ j.gastro.2004.12.008

Jensen, J., Pedersen, E. E., Galante, P., Hald, J., Heller, R. S., Ishibashi, M., et al. (2000). Control of Endodermal Endocrine Development by Hes-1. Nat. Genet. 24, 36-44. doi:10.1038/71657

Jia, D., Sun, Y., and Konieczny, S. F. (2008). Mist1 Regulates Pancreatic Acinar Cell Proliferation through p21CIP1/WAF1. Gastroenterology 135, 1687-1697. doi:10.1053/j.gastro.2008.07.026

Johansson, K. A., Dursun, U., Jordan, N., Gu, G., Beermann, F., Gradwohl, G., et al. (2007). Temporal Control of Neurogenin3 Activity in Pancreas Progenitors Reveals Competence Windows for the Generation of Different Endocrine Cell Types. Develop. Cel. 12, 457-465. doi:10.1016/j.devcel.2007.02.010

Johnson, C. L., Kowalik, A. S., Rajakumar, N., and Pin, C. L. (2004). Mist1 Is Necessary for the Establishment of Granule Organization in Serous Exocrine Cells of the Gastrointestinal Tract. Mech. Develop. 121, 261-272. doi:10.1016/ j.mod.2004.01.003

Jolly, M. K., Boareto, M., Huang, B., Jia, D., Lu, M., Onuchic, J. N., et al. (2015). Implications of the Hybrid Epithelial/mesenchymal Phenotype in Metastasis. Front. Oncol. 5, 155. doi:10.3389/fonc.2015.00155

Jonsson, J., Carlsson, L., Edlund, T., and Edlund, H. (1994). Insulin-promoterfactor 1 Is Required for Pancreas Development in Mice. Nature 371, 606-609. doi:10.1038/371606a0

Kapoor, A., Yao, W., Ying, H., Hua, S., Liewen, A., Wang, Q., et al. (2014). Yap1 Activation Enables Bypass of Oncogenic KRAS Addiction in Pancreatic Cancer. Cell 158, 185-197. doi:10.1016/j.cell.2014.06.003

Kar, A., and Gutierrez-Hartmann, A. (2013). Molecular Mechanisms of ETS Transcription Factor-Mediated Tumorigenesis. Crit. Rev. Biochem. Mol. Biol. 48, 522-543. doi:10.3109/10409238.2013.838202

Ketola, I., Otonkoski, T., Pulkkinen, M.-A., Niemi, H., Palgi, J., Jacobsen, C. M., et al. (2004). Transcription Factor GATA-6 Is Expressed in the Endocrine and GATA-4 in the Exocrine Pancreas. Mol. Cell Endocrinol. 226, 51-57. doi:10.1016/j.mce.2004.06.007

Kimura, Y., Fukuda, A., Ogawa, S., Maruno, T., Takada, Y., Tsuda, M., et al. (2018). ARID1A Maintains Differentiation of Pancreatic Ductal Cells and Inhibits Development of Pancreatic Ductal Adenocarcinoma in Mice. Gastroenterology 155, 194-209. e2. doi:10.1053/j.gastro.2018.03.039

Klemm, S. L., Shipony, Z., and Greenleaf, W. J. (2019). Chromatin Accessibility and the Regulatory Epigenome. Nat. Rev. Genet. 20, 207-220. doi:10.1038/s41576018-0089-8

Kopinke, D., Brailsford, M., Shea, J. E., Leavitt, R., Scaife, C. L., and Murtaugh, L. C. (2011). Lineage Tracing Reveals the Dynamic Contribution of Hes1+ Cells to the Developing and Adult Pancreas. Development 138, 431-441. doi:10.1242/ dev. 053843

Kopp, J. L., von Figura, G., Mayes, E., Liu, F.-F., Dubois, C. L., Morris, J. P., et al. (2012). Identification of Sox9-dependent Acinar-To-Ductal Reprogramming as the Principal Mechanism for Initiation of Pancreatic Ductal Adenocarcinoma. Cancer Cell 22, 737-750. doi:10.1016/j.ccr.2012.10.025

Krah, N. M., De La O, J.-P., Swift, G. H., Hoang, C. Q., Willet, S. G., Chen Pan, F., et al. (2015). The Acinar Differentiation Determinant PTF1A Inhibits Initiation of Pancreatic Ductal Adenocarcinoma. Elife 4, e07125. doi:10.7554/elife.07125

Krah, N. M., Narayanan, S. M., Yugawa, D. E., Straley, J. A., Wright, C. V. E., MacDonald, R. J., et al. (2019). Prevention and Reversion of Pancreatic Tumorigenesis through a Differentiation-Based Mechanism. Develop. Cel. 50, 744-754. e4. doi:10.1016/j.devcel.2019.07.012

Krebs, A. M., Mitschke, J., Lasierra Losada, M., Schmalhofer, O., Boerries, M., Busch, H., et al. (2017). The EMT-Activator Zeb1 Is a Key Factor for Cell Plasticity and Promotes Metastasis in Pancreatic Cancer. Nat. Cel. Biol. 19, 518-529. doi:10.1038/ncb3513

Lambert, A. W., Pattabiraman, D. R., and Weinberg, R. A. (2017). Emerging Biological Principles of Metastasis. Cell 168, 670-691. doi:10.1016/ j.cell.2016.11.037

Lambert, S. A., Jolma, A., Campitelli, L. F., Das, P. K., Yin, Y., Albu, M., et al. (2018). The Human Transcription Factors. Cell 172, 650-665. doi:10.1016/ j.cell.2018.01.029 
Larsen, H. L., and Grapin-Botton, A. (2017). The Molecular and Morphogenetic Basis of Pancreas Organogenesis. Semin. Cel. Develop. Biol. 66, 51-68. doi:10.1016/j.semcdb.2017.01.005

Lasierra Losada, M., Pauler, M., Vandamme, N., Goossens, S., Berx, G., Leppkes, M., et al. (2021). Pancreas Morphogenesis and Homeostasis Depends on Tightly Regulated Zeb1 Levels in Epithelial Cells. Cell Death Discov. 7, 138. doi:10.1038/s41420-021-00522-Z

Lee, T. I., and Young, R. A. (2013). Transcriptional Regulation and its Misregulation in Disease. Cell 152, 1237-1251. doi:10.1016/j.cell.2013.02.014

Li, H., Arber, S., Jessell, T. M., and Edlund, H. (1999). Selective Agenesis of the Dorsal Pancreas in Mice Lacking Homeobox Gene Hlxb9. Nat. Genet. 23, 67-70. doi:10.1038/12669

Liu, S., Ballian, N., Belaguli, N. S., Patel, S., Li, M., Templeton, N. S., et al. (2008). PDX-1 Acts as a Potential Molecular Target for Treatment of Human Pancreatic Cancer. Pancreas 37, 210-220. doi:10.1097/mpa.0b013e31816a4a33

Lomberk, G., Blum, Y., Nicolle, R., Nair, A., Gaonkar, K. S., Marisa, L., et al. (2018). Distinct Epigenetic Landscapes Underlie the Pathobiology of Pancreatic Cancer Subtypes. Nat. Commun. 9, 1978. doi:10.1038/s41467-018-04383-6

Lorberbaum, D. S., Docherty, F. M., and Sussel, L. (2020). Animal Models of Pancreas Development, Developmental Disorders, and Disease. Adv. Exp. Med. Biol. 1236, 65-85. Available at: https://www.ncbi.nlm.nih.gov/pubmed/ 32304069. doi:10.1007/978-981-15-2389-2_3

Lu, W., and Kang, Y. (2019). Epithelial-Mesenchymal Plasticity in Cancer Progression and Metastasis. Develop. Cel. 49, 361-374. doi:10.1016/ j.devcel.2019.04.010

Lu, Y., Chan, Y.-T., Tan, H.-Y., Li, S., Wang, N., and Feng, Y. (2020). Epigenetic Regulation in Human Cancer: the Potential Role of Epi-Drug in Cancer Therapy. Mol. Cancer 19, 79. doi:10.1186/s12943-020-01197-3

Luo, Z., Li, Y., Wang, H., Fleming, J., Li, M., Kang, Y., et al. (2015). Hepatocyte Nuclear Factor 1A (HNF1A) as a Possible Tumor Suppressor in Pancreatic Cancer. PLoS One 10, e0121082. doi:10.1371/journal.pone.0121082

Lüttges, J., Galehdari, H., Bröcker, V., Schwarte-Waldhoff, I., Henne-Bruns, D., Klöppel, G., et al. (2001). Allelic Loss Is Often the First Hit in the Biallelic Inactivation of the P53 and DPC4 Genes during Pancreatic Carcinogenesis. Am. J. Pathol. 158, 1677-1683. doi:10.1016/S0002-9440(10)64123-5

Macgregor-Das, A. M., and Iacobuzio-Donahue, C. A. (2013). Molecular Pathways in Pancreatic Carcinogenesis. J. Surg. Oncol. 107, 8-14. doi:10.1002/jso.23213

Magenheim, J., Klein, A. M., Stanger, B. Z., Ashery-Padan, R., Sosa-Pineda, B., Gu, G., et al. (2011). Ngn3+ Endocrine Progenitor Cells Control the Fate and Morphogenesis of Pancreatic Ductal Epithelium. Develop. Biol. 359, 26-36. doi:10.1016/j.ydbio.2011.08.006

Maitra, A., Adsay, N. V., Argani, P., Iacobuzio-Donahue, C., De Marzo, A., Cameron, J. L., et al. (2003). Multicomponent Analysis of the Pancreatic Adenocarcinoma Progression Model Using a Pancreatic Intraepithelial Neoplasia Tissue Microarray. Mod. Pathol. 16, 902-912. doi:10.1097/ 01.mp.0000086072.56290.fb

Maity, G., Haque, I., Ghosh, A., Dhar, G., Gupta, V., Sarkar, S., et al. (2018). The MAZ Transcription Factor Is a Downstream Target of the Oncoprotein Cyr61/ CCN1 and Promotes Pancreatic Cancer Cell Invasion via CRAF-ERK Signaling. J. Biol. Chem. 293, 4334-4349. doi:10.1074/jbc.ra117.000333

Makohon-Moore, A. P., Zhang, M., Reiter, J. G., Bozic, I., Allen, B., Kundu, D., et al. (2017). Limited Heterogeneity of Known Driver Gene Mutations Among the Metastases of Individual Patients with Pancreatic Cancer. Nat. Genet. 49, 358-366. doi:10.1038/ng.3764

Marchand, B., Pitarresi, J. R., Reichert, M., Suzuki, K., Laczkó, D., and Rustgi, A. K. (2019). PRRX1 Isoforms Cooperate with FOXM1 to Regulate the DNA Damage Response in Pancreatic Cancer Cells. Oncogene 38, 4325-4339. doi:10.1038/ s41388-019-0725-6

Martinelli, P., Cañamero, M., del Pozo, N., Madriles, F., Zapata, A., and Real, F. X. (2013). Gata6is Required for Complete Acinar Differentiation and Maintenance of the Exocrine Pancreas in Adult Mice. Gut 62, 1481-1488. doi:10.1136/gutjnl2012-303328

Martinelli, P., Carrillo-De Santa Pau, E., Cox, T., Sainz, B., Dusetti, N., Greenhalf, W., et al. (2017). GATA6 Regulates EMT and Tumour Dissemination, and Is a Marker of Response to Adjuvant Chemotherapy in Pancreatic Cancer. Gut 66, 1665-1676. doi:10.1136/gutjnl-2015-311256

Martinelli, P., Madriles, F., Cañamero, M., Pau, E. C.-d. S., Pozo, N. D., Guerra, C., et al. (2016). The Acinar Regulator Gata6 suppressesKrasG12V-Driven
Pancreatic Tumorigenesis in Mice. Gut 65, 476-486. doi:10.1136/gutjnl2014-308042

Massagué, J. (2008). TGF $\beta$ in Cancer. Cell 134, 215-230. doi:10.1016/ j.cell.2008.07.001

Mazur, P. K., Einwächter, H., Lee, M., Sipos, B., Nakhai, H., Rad, R., et al. (2010). Notch2 Is Required for Progression of Pancreatic Intraepithelial Neoplasia and Development of Pancreatic Ductal Adenocarcinoma. Proc. Natl. Acad. Sci. 107, 13438-13443. doi:10.1073/pnas.1002423107

McCormack, N., and O'Dea, S. (2013). Regulation of Epithelial to Mesenchymal Transition by Bone Morphogenetic Proteins. Cell Signal. 25, 2856-2862. doi:10.1016/j.cellsig.2013.09.012

McDonald, O. G., Li, X., Saunders, T., Tryggvadottir, R., Mentch, S. J., Warmoes, M. O., et al. (2017). Epigenomic Reprogramming during Pancreatic Cancer Progression Links Anabolic Glucose Metabolism to Distant Metastasis. Nat. Genet. 49, 367-376. doi:10.1038/ng.3753

Means, A. L., Meszoely, I. M., Suzuki, K., Miyamoto, Y., Rustgi, A. K., Coffey, R. J., Jr., et al. (2005). Pancreatic Epithelial Plasticity Mediated by Acinar Cell Transdifferentiation and Generation of Nestin-Positive Intermediates. Development 132, 3767-3776. doi:10.1242/dev.01925

Meidhof, S., Brabletz, S., Lehmann, W., Preca, B. T., Mock, K., Ruh, M., et al. (2015). ZEB 1-associated Drug Resistance in Cancer Cells Is Reversed by the Class I HDAC Inhibitor Mocetinostat. EMBO Mol. Med. 7, 831-847. doi:10.15252/emmm.201404396

Meng, F., Takaori, K., Ito, T., Masui, T., Kawaguchi, M., Kawaguchi, Y., et al. (2014). Expression of SOX9 in Intraductal Papillary Mucinous Neoplasms of the Pancreas. Pancreas 43, 7-14. doi:10.1097/mpa.0b013e3182a70b2f

Mihalko, E. P., and Brown, A. C. (2018). Material Strategies for Modulating Epithelial to Mesenchymal Transitions. ACS Biomater. Sci. Eng. 4, 1149-1161. doi:10.1021/acsbiomaterials.6b00751

Miyamoto, Y., Maitra, A., Ghosh, B., Zechner, U., Argani, P., Iacobuzio-Donahue, C. A., et al. (2003). Notch Mediates TGFa-Induced Changes in Epithelial Differentiation during Pancreatic Tumorigenesis. Cancer Cell 3, 565-576. doi:10.1016/s1535-6108(03)00140-5

Miyatsuka, T., Kaneto, H., Shiraiwa, T., Matsuoka, T. A., Yamamoto, K., Kato, K., et al. (2006). Persistent Expression of PDX-1 in the Pancreas Causes Acinar-ToDuctal Metaplasia through Stat3 Activation. Genes Develop. 20, 1435-1440. doi:10.1101/gad.1412806

Moffitt, R. A., Marayati, R., Flate, E. L., Volmar, K. E., Loeza, S. G. H., Hoadley, K. A., et al. (2015). Virtual Microdissection Identifies Distinct Tumor- and Stroma-specific Subtypes of Pancreatic Ductal Adenocarcinoma. Nat. Genet. 47, 1168-1178. doi:10.1038/ng.3398

Molero, X., Adell, T., Skoudy, A., Padilla, M. A., Gómez, J. A., Chalaux, E., et al. (2007). Pancreas Transcription Factor 1? Expression Is Regulated in Pancreatitis. Eur. J. Clin. Invest. 37, 791-801. doi:10.1111/j.13652362.2007.01856.x

Moore, M. J., Goldstein, D., Hamm, J., Figer, A., Hecht, J. R., Gallinger, S., et al. (2007). Erlotinib Plus Gemcitabine Compared with Gemcitabine Alone in Patients with Advanced Pancreatic Cancer: a Phase III Trial of the National Cancer Institute of Canada Clinical Trials Group. Jco 25, 1960-1966. doi:10.1200/jco.2006.07.9525

Morris, J. P., Cano, D. A., Sekine, S., Wang, S. C., and Hebrok, M. (2010). $\beta$-Catenin Blocks Kras-dependent Reprogramming of Acini into Pancreatic Cancer Precursor Lesions in Mice. J. Clin. Invest. 120, 508-520. doi:10.1172/jci40045

Morton, J. P., Timpson, P., Karim, S. A., Ridgway, R. A., Athineos, D., Doyle, B., et al. (2010). Mutant P53 Drives Metastasis and Overcomes Growth Arrest/ senescence in Pancreatic Cancer. Proc. Natl. Acad. Sci. 107, 246-251. doi:10.1073/pnas.0908428107

Murakami, S., Nemazanyy, I., White, S. M., Chen, H., Nguyen, C. D. K., Graham, G. T., et al. (2019). A Yap-Myc-Sox2-P53 Regulatory Network Dictates Metabolic Homeostasis and Differentiation in Kras-Driven Pancreatic Ductal Adenocarcinomas. Develop. Cel. 51, 113-128. e9. doi:10.1016/ j.devcel.2019.07.022

Murtaugh, L. C., Stanger, B. Z., Kwan, K. M., and Melton, D. A. (2003). Notch Signaling Controls Multiple Steps of Pancreatic Differentiation. Proc. Natl. Acad. Sci. 100, 14920-14925. doi:10.1073/pnas.2436557100

Neesse, A., Michl, P., Frese, K. K., Feig, C., Cook, N., Jacobetz, M. A., et al. (2011). Stromal Biology and Therapy in Pancreatic Cancer. Gut 60, 861-868. doi:10.1136/gut.2010.226092 
Nicolle, R., Blum, Y., Marisa, L., Loncle, C., Gayet, O., Moutardier, V., et al. (2017). Pancreatic Adenocarcinoma Therapeutic Targets Revealed by Tumor-Stroma Cross-Talk Analyses in Patient-Derived Xenografts. Cel. Rep. 21, 2458-2470. doi:10.1016/j.celrep.2017.11.003

Nieto, M. A., Huang, R. Y.-J., Jackson, R. A., and Thiery, J. P. (2016). Emt: 2016. Cell 166, 21-45. doi:10.1016/j.cell.2016.06.028

Nishikawa, Y., Kodama, Y., Shiokawa, M., Matsumori, T., Marui, S., Kuriyama, K., et al. (2019). Hes1 Plays an Essential Role in Kras-Driven Pancreatic Tumorigenesis. Oncogene 38, 4283-4296. doi:10.1038/s41388-019-0718-5

Offield, M. F., Jetton, T. L., Labosky, P. A., Ray, M., Stein, R. W., Magnuson, M. A., et al. (1996). PDX-1 Is Required for Pancreatic Outgrowth and Differentiation of the Rostral Duodenum. Development 122, 983-995. doi:10.1242/ dev.122.3.983

Orth, M., Metzger, P., Gerum, S., Mayerle, J., Schneider, G., Belka, C., et al. (2019). Pancreatic Ductal Adenocarcinoma: Biological Hallmarks, Current Status, and Future Perspectives of Combined Modality Treatment Approaches. Radiat. Oncol. 14, 141. doi:10.1186/s13014-019-1345-6

Pan, F. C., and Wright, C. (2011). Pancreas Organogenesis: from Bud to Plexus to Gland. Dev. Dyn. 240, 530-565. doi:10.1002/dvdy.22584

Park, J. Y., Hong, S.-M., Klimstra, D. S., Goggins, M. G., Maitra, A., and Hruban, R. H. (2011). Pdx1 Expression in Pancreatic Precursor Lesions and Neoplasms. Appl. Immunohistochem. Mol. Morphol. 19, 444-449. doi:10.1097/ pai.0b013e318206d 958

Parsa, I., Longnecker, D. S., Scarpelli, D. G., Pour, P., Reddy, J. K., and Lefkowitz, M. (1985). Ductal Metaplasia of Human Exocrine Pancreas and its Association with Carcinoma. Cancer Res. 45, 1285-1290.

Patil, S., Steuber, B., Kopp, W., Kari, V., Urbach, L., Wang, X., et al. (2020). EZH2 Regulates Pancreatic Cancer Subtype Identity and Tumor Progression via Transcriptional Repression of Gata6. Cancer Res. 80, 4620-4632. doi:10.1158/0008-5472.can-20-0672

Pin, C. L., Rukstalis, J. M., Johnson, C., and Konieczny, S. F. (2001). The bHLH Transcription Factor Mist1 Is Required to Maintain Exocrine Pancreas Cell Organization and Acinar Cell Identity. J. Cel. Biol. 155, 519-530. doi:10.1083/ jcb.200105060

Plentz, R., Park, J. S., Rhim, A. D., Abravanel, D., Hezel, A. F., Sharma, S. V., et al. (2009). Inhibition of $\gamma$-Secretase Activity Inhibits Tumor Progression in a Mouse Model of Pancreatic Ductal Adenocarcinoma. Gastroenterology 136, 1741-1749. e6. doi:10.1053/j.gastro.2009.01.008

Preca, B.-T., Bajdak, K., Mock, K., Lehmann, W., Sundararajan, V., Bronsert, P., et al. (2017). A Novel ZEB1/HAS2 Positive Feedback Loop Promotes EMT in Breast Cancer. Oncotarget 8, 11530-11543. doi:10.18632/oncotarget.14563

Preca, B.-T., Bajdak, K., Mock, K., Sundararajan, V., Pfannstiel, J., Maurer, J., et al. (2015). A Self-Enforcing CD44s/ZEB1 Feedback Loop Maintains EMT and Stemness Properties in Cancer Cells. Int. J. Cancer 137, 2566-2577. doi:10.1002/ ijc. 29642

Prévot, P.-P., Simion, A., Grimont, A., Colletti, M., Khalaileh, A., Van den Steen, G., et al. (2012). Role of the Ductal Transcription Factors HNF6 and Sox9 in Pancreatic Acinar-To-Ductal Metaplasia. Gut 61, 1723-1732. doi:10.1136/ gutjnl-2011-300266

Puleo, F., Nicolle, R., Blum, Y., Cros, J., Marisa, L., Demetter, P., et al. (2018). Stratification of Pancreatic Ductal Adenocarcinomas Based on Tumor and Microenvironment Features. Gastroenterology 155, 1999-2013. e3. doi:10.1053/ j.gastro.2018.08.033

Raphael, B. J., Hruban, R. H., Aguirre, A. J., Moffitt, R. A., Yeh, J. J., Stewart, C., et al. (2017). Integrated Genomic Characterization of Pancreatic Ductal Adenocarcinoma. Cancer Cell 32, 185-e13. e13. doi:10.1016/j.ccell.2017.07.007

Ray, K. C., Bell, K. M., Yan, J., Gu, G., Chung, C. H., Washington, M. K., et al. (2011). Epithelial Tissues Have Varying Degrees of Susceptibility to KrasG12DInitiated Tumorigenesis in a Mouse Model. PLoS One 6, e16786. doi:10.1371/ journal.pone.0016786

Recouvreux, M. V., Moldenhauer, M. R., Galenkamp, K. M. O., Jung, M., James, B., Zhang, Y., et al. (2020). Glutamine Depletion Regulates Slug to Promote EMT and Metastasis in Pancreatic Cancer. J. Exp. Med. 217, e20200388. doi:10.1084/ jem.20200388

Reichert, M., Blume, K., Kleger, A., Hartmann, D., and Von Figura, G. (2016). Developmental Pathways Direct Pancreatic Cancer Initiation from its Cellular Origin. Stem Cell Int. 2016, 1-8. doi:10.1155/2016/9298535
Robertson, J. F. R., Coleman, R. E., Cheung, K.-L., Evans, A., Holcombe, C., Skene, A., et al. (2020). Proliferation and AKT Activity Biomarker Analyses after Capivasertib (AZD5363) Treatment of Patients with ER+ Invasive Breast Cancer (STAKT). Clin. Cancer Res. 26, 1574-1585. doi:10.1158/10780432.ccr-19-3053

Roe, J.-S., Hwang, C.-I., Somerville, T. D. D., Milazzo, J. P., Lee, E. J., Da Silva, B., et al. (2017). Enhancer Reprogramming Promotes Pancreatic Cancer Metastasis. Cell 170, 875-888. e20. doi:10.1016/j.cell.2017.07.007

Rosado-Olivieri, E. A., Anderson, K., Kenty, J. H., and Melton, D. A. (2019). YAP Inhibition Enhances the Differentiation of Functional Stem Cell-Derived Insulin-Producing $\beta$ Cells. Nat. Commun. 10, 1464. doi:10.1038/s41467-01909404-6

Rose, S. D., Swift, G. H., Peyton, M. J., Hammer, R. E., and MacDonald, R. J. (2001). The Role of PTF1-P48 in Pancreatic Acinar Gene Expression. J. Biol. Chem. 276, 44018-44026. doi:10.1074/jbc.m106264200

Roy, N., Takeuchi, K. K., Ruggeri, J. M., Bailey, P., Chang, D., Li, J., et al. (2016). PDX1 Dynamically Regulates Pancreatic Ductal Adenocarcinoma Initiation and Maintenance. Genes Dev. 30, 2669-2683. doi:10.1101/gad.291021.116

Rukstalis, J. M., and Habener, J. F. (2007). Snail2, a Mediator of EpithelialMesenchymal Transitions, Expressed in Progenitor Cells of the Developing Endocrine Pancreas. Gene Expr. Patterns 7, 471-479. doi:10.1016/ j.modgep.2006.11.001

Salim, K. Y., Maleki Vareki, S., Danter, W. R., San-Marina, S., and Koropatnick, J. (2016). COTI-2, a Novel Small Molecule that Is Active against Multiple Human Cancer Cell Lines In Vitro and In Vivo. Oncotarget 7, 41363-41379. doi:10.18632/oncotarget.9133

Sato, M., Matsumoto, M., Saiki, Y., Alam, M., Nishizawa, H., Rokugo, M., et al. (2020). BACH1 Promotes Pancreatic Cancer Metastasis by Repressing Epithelial Genes and Enhancing Epithelial-Mesenchymal Transition. Cancer Res. 80, 1279-1292. doi:10.1158/0008-5472.can-18-4099

Satoh, K., Hamada, S., and Shimosegawa, T. (2015). Involvement of Epithelial to Mesenchymal Transition in the Development of Pancreatic Ductal Adenocarcinoma. J. Gastroenterol. 50, 140-146. doi:10.1007/s00535-0140997-0

Schaffer, A. E., Taylor, B. L., Benthuysen, J. R., Liu, J., Thorel, F., Yuan, W., et al. (2013). Nkx6.1 Controls a Gene Regulatory Network Required for Establishing and Maintaining Pancreatic Beta Cell Identity. Plos Genet. 9, e1003274. doi:10.1371/journal.pgen.1003274

Seino, T., Kawasaki, S., Shimokawa, M., Tamagawa, H., Toshimitsu, K., Fujii, M., et al. (2018). Human Pancreatic Tumor Organoids Reveal Loss of Stem Cell Niche Factor Dependence during Disease Progression. Cell Stem Cell 22, 454-467. e6. doi:10.1016/j.stem.2017.12.009

Seo, S. R., Lallemand, F., Ferrand, N., Pessah, M., L'Hoste, S., Camonis, J., et al. (2004). The Novel E3 Ubiquitin Ligase Tiul1 Associates with TGIF to Target Smad2 for Degradation. EMBO J. 23, 3780-3792. doi:10.1038/sj.emboj.7600398

Seymour, P. A., Freude, K. K., Tran, M. N., Mayes, E. E., Jensen, J., Kist, R., et al. (2007). SOX9 Is Required for Maintenance of the Pancreatic Progenitor Cell Pool. Proc. Natl. Acad. Sci. 104, 1865-1870. doi:10.1073/pnas.0609217104

Seymour, P. A., Shih, H. P., Patel, N. A., Freude, K. K., Xie, R., Lim, C. J., et al. (2012). A Sox $9 /$ Fgf Feed-Forward Loop Maintains Pancreatic Organ Identity. Development 139, 3363-3372. doi:10.1242/dev.078733

Shaw-Smith, C., De Franco, E., Lango Allen, H., Batlle, M., Flanagan, S. E., Borowiec, M., et al. (2014). GATA4 Mutations Are a Cause of Neonatal and Childhood-Onset Diabetes. Diabetes 63, 2888-2894. doi:10.2337/db14-0061

Shen, H., and Laird, P. W. (2013). Interplay between the Cancer Genome and Epigenome. Cell 153, 38-55. doi:10.1016/j.cell.2013.03.008

Shi, G., DiRenzo, D., Qu, C., Barney, D., Miley, D., and Konieczny, S. F. (2013). Maintenance of Acinar Cell Organization Is Critical to Preventing KrasInduced Acinar-Ductal Metaplasia. Oncogene 32, 1950-1958. doi:10.1038/ onc.2012.210

Shi, G., Zhu, L., Sun, Y., Bettencourt, R., Damsz, B., Hruban, R. H., et al. (2009). Loss of the Acinar-Restricted Transcription Factor Mistl Accelerates KrasInduced Pancreatic Intraepithelial Neoplasia. Gastroenterology 136, 1368-1378. doi:10.1053/j.gastro.2008.12.066

Shichi, Y., Sasaki, N., Michishita, M., Hasegawa, F., Matsuda, Y., Arai, T., et al. (2019). Enhanced Morphological and Functional Differences of Pancreatic 
Cancer with Epithelial or Mesenchymal Characteristics in 3D Culture. Sci. Rep. 9, 10871. doi:10.1038/s41598-019-47416-w

Shih, H. P., Seymour, P. A., Patel, N. A., Xie, R., Wang, A., Liu, P. P., et al. (2015). A Gene Regulatory Network Cooperatively Controlled by Pdx1 and Sox9 Governs Lineage Allocation of Foregut Progenitor Cells. Cel. Rep. 13, 326-336. doi:10.1016/j.celrep.2015.08.082

Shih, H. P., Wang, A., and Sander, M. (2013). Pancreas Organogenesis: from Lineage Determination to Morphogenesis. Annu. Rev. Cel. Dev. Biol. 29, 81-105. doi:10.1146/annurev-cellbio-101512-122405

Shroff, S., Rashid, A., Wang, H., Katz, M. H., Abbruzzese, J. L., Fleming, J. B., et al. (2014). SOX9: a Useful Marker for Pancreatic Ductal Lineage of Pancreatic Neoplasms. Hum. Pathol. 45, 456-463. doi:10.1016/j.humpath.2013.10.008

Singh, A., Greninger, P., Rhodes, D., Koopman, L., Violette, S., Bardeesy, N., et al. (2009). A Gene Expression Signature Associated with "K-Ras Addiction" Reveals Regulators of EMT and Tumor Cell Survival. Cancer Cell 15, 489-500. doi:10.1016/j.ccr.2009.03.022

Sinn, M., Bahra, M., Liersch, T., Gellert, K., Messmann, H., Bechstein, W., et al. (2017). CONKO-005: Adjuvant Chemotherapy with Gemcitabine Plus Erlotinib versus Gemcitabine Alone in Patients after R0 Resection of Pancreatic Cancer: A Multicenter Randomized Phase III Trial. Jco 35, 3330-3337. doi:10.1200/jco.2017.72.6463

Slack, J. M. W. (2007). Metaplasia and Transdifferentiation: from Pure Biology to the Clinic. Nat. Rev. Mol. Cel. Biol. 8, 369-378. doi:10.1038/nrm2146

Somerville, T. D. D., Xu, Y., Miyabayashi, K., Tiriac, H., Cleary, C. R., Maia-Silva, D., et al. (2018). TP63-Mediated Enhancer Reprogramming Drives the Squamous Subtype of Pancreatic Ductal Adenocarcinoma. Cel. Rep. 25, 1741-1755. e7. doi:10.1016/j.celrep.2018.10.051

Song, S. Y., Gannon, M., Washington, M. K., Scoggins, C. R., Meszoely, I. M., Goldenring, J. R., et al. (1999). Expansion of Pdx1-Expressing Pancreatic Epithelium and Islet Neogenesis in Transgenic Mice Overexpressing Transforming Growth Factor a. Gastroenterology 117, 1416-1426. doi:10.1016/s0016-5085(99)70292-1

Song, Y., Washington, M. K., and Crawford, H. C. (2010). Loss of FOXA1/2 Is Essential for the Epithelial-To-Mesenchymal Transition in Pancreatic Cancer. Cancer Res. 70, 2115-2125. doi:10.1158/0008-5472.can-09-2979

Sousa, C. M., and Kimmelman, A. C. (2014). The Complex Landscape of Pancreatic Cancer Metabolism. Carcinogenesis 35, 1441-1450. doi:10.1093/carcin/bgu097

Stanger, B. Z., and Hebrok, M. (2013). Control of Cell Identity in Pancreas Development and Regeneration. Gastroenterology 144, 1170-1179. doi:10.1053/j.gastro.2013.01.074

Stemmler, M. P., Eccles, R. L., Brabletz, S., and Brabletz, T. (2019). Non-redundant Functions of EMT Transcription Factors. Nat. Cel. Biol. 21, 102-112. doi:10.1038/s41556-018-0196-y

Storz, P. (2017). Acinar Cell Plasticity and Development of Pancreatic Ductal Adenocarcinoma. Nat. Rev. Gastroenterol. Hepatol. 14, 296-304. doi:10.1038/ nrgastro.2017.12

Subramani, R., Medel, J., Flores, K., Perry, C., Galvez, A., Sandoval, M., et al. (2020). Hepatocyte Nuclear Factor 1 Alpha Influences Pancreatic Cancer Growth and Metastasis. Sci. Rep. 10, 20225. doi:10.1038/s41598-020-77287-5

Swayden, M., Iovanna, J., and Soubeyran, P. (2018). Pancreatic Cancer ChemoResistance Is Driven by Tumor Phenotype rather Than Tumor Genotype. Heliyon 4, e01055. doi:10.1016/j.heliyon.2018.e01055

Taipale, J., and Beachy, P. A. (2001). The Hedgehog and Wnt Signalling Pathways in Cancer. Nature 411, 349-354. doi:10.1038/35077219

Takano, S., Reichert, M., Bakir, B., Das, K. K., Nishida, T., Miyazaki, M., et al. (2016). Prrx1 Isoform Switching Regulates Pancreatic Cancer Invasion and Metastatic Colonization. Genes Dev. 30, 233-247. doi:10.1101/gad.263327.115

Tam, S. Y., Wu, V. W. C., and Law, H. K. W. (2020). Hypoxia-Induced EpithelialMesenchymal Transition in Cancers: HIF-1 $\alpha$ and beyond. Front. Oncol. 10, 486. doi: $10.3389 /$ fonc. 2020.00486

Tanaka, T., Kuroki, T., Adachi, T., Ono, S., Hirabaru, M., Soyama, A., et al. (2013). Evaluation of SOX9 Expression in Pancreatic Ductal Adenocarcinoma and Intraductal Papillary Mucinous Neoplasm. Pancreas 42, 488-493. doi:10.1097/ mpa.0b013e318269d281

Thompson, N., Gesina, E., Scheinert, P., Bucher, P., and Grapin-Botton, A. (2012). RNA Profiling and Chromatin Immunoprecipitation-Sequencing Reveal that PTF1a Stabilizes Pancreas Progenitor Identity via the Control of MNX1/
HLXB9 and a Network of Other Transcription Factors. Mol. Cell Biol. 32, 1189-1199. doi:10.1128/mcb.06318-11

Titov, D. V., Gilman, B., He, Q.-L., Bhat, S., Low, W.-K., Dang, Y., et al. (2011). XPB, a Subunit of TFIIH, Is a Target of the Natural Product Triptolide. Nat. Chem. Biol. 7, 182-188. doi:10.1038/nchembio.522

Tuerhong, A., Xu, J., Shi, S., Tan, Z., Meng, Q., Hua, J., et al. (2021). Overcoming Chemoresistance by Targeting Reprogrammed Metabolism: the Achilles' Heel of Pancreatic Ductal Adenocarcinoma. Cel. Mol. Life Sci. 78, 5505-5526. doi:10.1007/s00018-021-03866-y

Viré, E., Brenner, C., Deplus, R., Blanchon, L., Fraga, M., Didelot, C., et al. (2006). The Polycomb Group Protein EZH2 Directly Controls DNA Methylation. Nature 439, 871-874. doi:10.1038/nature04431

Vispé, S., DeVries, L., Créancier, L., Besse, J., Bréand, S., Hobson, D. J., et al. (2009). Triptolide Is an Inhibitor of RNA Polymerase I and II-dependent Transcription Leading Predominantly to Down-Regulation of Short-Lived mRNA. Mol. Cancer Ther. 8, 2780-2790. doi:10.1158/1535-7163.mct-09-0549

Völkel, P., Dupret, B., Le Bourhis, X., and Angrand, P. O. (2015). Diverse Involvement of EZH2 in Cancer Epigenetics. Am. J. Transl. Res. 7, 175-193. von Figura, G., Morris, J. P., Wright, C. V. E., and Hebrok, M. (2014). Nr5a2 Maintains Acinar Cell Differentiation and Constrains Oncogenic KrasMediated Pancreatic Neoplastic Initiation. Gut 63, 656-664. doi:10.1136/ gutjnl-2012-304287

Wang, L., Yang, H., Abel, E. V., Ney, G. M., Palmbos, P. L., Bednar, F., et al. (2015). ATDC Induces an Invasive Switch in KRAS-Induced Pancreatic Tumorigenesis. Genes Dev. 29, 171-183. doi:10.1101/gad.253591.114

Watt, A. J., Zhao, R., Li, J., and Duncan, S. A. (2007). Development of the Mammalian Liver and Ventral Pancreas Is Dependent on GATA4. BMC Dev. Biol. 7, 37. doi:10.1186/1471-213x-7-37

Weissman, S., Takakura, K., Eibl, G., Pandol, S. J., and Saruta, M. (2020). The Diverse Involvement of Cigarette Smoking in Pancreatic Cancer Development and Prognosis. Pancreas 49, 612-620. doi:10.1097/ mpa.0000000000001550

Weissmueller, S., Manchado, E., Saborowski, M., Morris, J. P., Wagenblast, E., Davis, C. A., et al. (2014). Mutant P53 Drives Pancreatic Cancer Metastasis through Cell-Autonomous PDGF Receptor $\beta$ Signaling. Cell 157, 382-394. doi:10.1016/j.cell.2014.01.066

Wellner, U., Schubert, J., Burk, U. C., Schmalhofer, O., Zhu, F., Sonntag, A., et al. (2009). The EMT-Activator ZEB1 Promotes Tumorigenicity by Repressing StemnessInhibiting microRNAs. Nat. Cel. Biol. 11, 1487-1495. doi:10.1038/ncb1998

Weng, C.-C., Hsieh, M.-J., Wu, C.-C., Lin, Y.-C., Shan, Y.-S., Hung, W.-C., et al. (2019). Loss of the Transcriptional Repressor TGIF1 Results in Enhanced KrasDriven Development of Pancreatic Cancer. Mol. Cancer 18, 96. doi:10.1186/ s12943-019-1023-1

Werner, J., Combs, S. E., Springfeld, C., Hartwig, W., Hackert, T., and Büchler, M. W. (2013). Advanced-stage Pancreatic Cancer: Therapy Options. Nat. Rev. Clin. Oncol. 10, 323-333. doi:10.1038/nrclinonc.2013.66

Whittle, M. C., Izeradjene, K., Rani, P. G., Feng, L., Carlson, M. A., DelGiorno, K. E., et al. (2015). RUNX3 Controls a Metastatic Switch in Pancreatic Ductal Adenocarcinoma. Cell 161, 1345-1360. doi:10.1016/j.cell.2015.04.048

Whyte, W. A., Orlando, D. A., Hnisz, D., Abraham, B. J., Lin, C. Y., Kagey, M. H., et al. (2013). Master Transcription Factors and Mediator Establish Super-enhancers at Key Cell Identity Genes. Cell 153, 307-319. doi:10.1016/j.cell.2013.03.035

Wiebe, P. O., Kormish, J. D., Roper, V. T., Fujitani, Y., Alston, N. I., Zaret, K. S., et al. (2007). Ptfla Binds to and Activates Area III, a Highly Conserved Region of the Pdx1 Promoter that Mediates Early Pancreas-wide Pdx1 Expression. Mol. Cel. Biol. 27, 4093-4104. doi:10.1128/mcb.01978-06

Wilentz, R. E., Iacobuzio-Donahue, C. A., Argani, P., McCarthy, D. M., Parsons, J. L., Yeo, C. J., et al. (2000). Loss of Expression of Dpc4 in Pancreatic Intraepithelial Neoplasia: Evidence that DPC4 Inactivation Occurs Late in Neoplastic Progression. Cancer Res. 60, 2002-2006.

Xiong, S., Feng, Y., and Cheng, L. (2019). Cellular Reprogramming as a Therapeutic Target in Cancer. Trends Cel. Biol. 29, 623-634. doi:10.1016/ j.tcb.2019.05.001

Xu, J., Liu, S., Yang, X., Cao, S., and Zhou, Y. (2020). Paracrine HGF Promotes EMT and Mediates the Effects of PSC on Chemoresistance by Activating C-Met/PI3K/Akt Signaling in Pancreatic Cancer In Vitro. Life Sci. 263, 118523. doi:10.1016/j.lfs.2020.118523 
Xuan, S., and Sussel, L. (2016). GATA4 and GATA6 Regulate Pancreatic Endoderm Identity through Inhibition of Hedgehog Signaling. Development 143, 780-786. doi:10.1242/dev.127217

Yachida, S., Jones, S., Bozic, I., Antal, T., Leary, R., Fu, B., et al. (2010). Distant Metastasis Occurs Late during the Genetic Evolution of Pancreatic Cancer. Nature 467, 1114-1117. doi:10.1038/nature09515

Yamada, S., Fujii, T., Shimoyama, Y., Kanda, M., Nakayama, G., Sugimoto, H., et al. (2015). SMAD4 Expression Predicts Local Spread and Treatment Failure in Resected Pancreatic Cancer. Pancreas 44, 660-664. doi:10.1097/mpa.0000000000000315

Yang, J., Ren, B., Yang, G., Wang, H., Chen, G., You, L., et al. (2020). The Enhancement of Glycolysis Regulates Pancreatic Cancer Metastasis. Cel. Mol. Life Sci. 77, 305-321. doi:10.1007/s00018-019-03278-z

Yuan, S., Natesan, R., Sanchez-Rivera, F. J., Li, J., Bhanu, N. V., Yamazoe, T., et al. (2020). Global Regulation of the Histone Mark H3K36ME2 Underlies Epithelial Plasticity and Metastatic Progression. Cancer Discov. 10, 854-871. doi:10.1158/ 2159-8290.cd-19-1299

Zhao, X., Liu, Z., Ren, Z., Wang, H., Wang, Z., Zhai, J., et al. (2020). Triptolide Inhibits Pancreatic Cancer Cell Proliferation and Migration via DownRegulating PLAU Based on Network Pharmacology of Tripterygium Wilfordii Hook F. Eur. J. Pharmacol. 880, 173225. doi:10.1016/ j.ejphar.2020.173225

Zheng, X., Carstens, J. L., Kim, J., Scheible, M., Kaye, J., Sugimoto, H., et al. (2015). Epithelial-to-mesenchymal Transition Is Dispensable for Metastasis but
Induces Chemoresistance in Pancreatic Cancer. Nature 527, 525-530. doi:10.1038/nature16064

Zhu, L., Shi, G., Schmidt, C. M., Hruban, R. H., and Konieczny, S. F. (2007). Acinar Cells Contribute to the Molecular Heterogeneity of Pancreatic Intraepithelial Neoplasia. Am. J. Pathol. 171, 263-273. doi:10.2353/ajpath.2007.061176

Conflict of Interest: The authors declare that the research was conducted in the absence of any commercial or financial relationships that could be construed as a potential conflict of interest.

Publisher's Note: All claims expressed in this article are solely those of the authors and do not necessarily represent those of their affiliated organizations, or those of the publisher, the editors and the reviewers. Any product that may be evaluated in this article, or claim that may be made by its manufacturer, is not guaranteed or endorsed by the publisher.

Copyright (C) 2021 van Roey, Brabletz, Stemmler and Armstark. This is an openaccess article distributed under the terms of the Creative Commons Attribution License (CC BY). The use, distribution or reproduction in other forums is permitted, provided the original author(s) and the copyright owner(s) are credited and that the original publication in this journal is cited, in accordance with accepted academic practice. No use, distribution or reproduction is permitted which does not comply with these terms. 


\section{GLOSSARY}

$\triangle$ NP63 deltaNp63 alternate variant of the tumor protein p63

3D three dimensional

ACTA2 (aSMA) actin alpha 2, smooth muscle

ADM acinar-ductal metaplasia

AKT/PKB AKT serine/threonine kinase 1/protein kinase B

ALDH1 aldehyde dehydrogenase 1

ATF4 activating transcription factor 4

BACH1 BTB domain and CNC homolog 1

BIRC5 baculoviral IAP repeat containing 5

BMP bone morphogenetic protein

BRCA2 breast cancer type 2 susceptibility protein

CCND1 cyclin D1

CDH1 cadherin 1/(epithelial) E-cadherin

CDH2 cadherin 2

CDKN2A cyclin dependent kinase inhibitor 2A

CDX2 caudal type homeobox 2

CK14 cytokeratin 14

CK19 cytokeratin 19

CRAF/Raf1 Raf-1 proto-oncogene, serine/threonine kinase

CSC cancer stem cell

CUX1 cut like homeobox 1

DNA deoxyribonucleic acid

E2F7 E2F transcription factor 7

EGF epidermal growth factor

EGFR epidermal growth factor receptor

ELF3 E74 like ETS transcription factor 3

EMT epithelial-mesenchymal transition

EPCAM epithelial cell adhesion molecule

ERK extracellular signal-regulated kinases

ESRP1 epithelial splicing regulatory protein 1

ETV1 ETS variant transcription factor 1

EZH2 enhancer of zeste 2 polycomb repressive complex 2 subunit

FAT2 FAT atypical cadherin 2

FBP1 fructose-bisphosphatase 1

FGF2 fibroblast growth factor 2

FN fibronectin 1

FOS Fos proto-oncogene, AP-1 transcription factor subunit

FOXA1 forkhead box protein A1

FOXA2 forkhead box protein A2

FOXP1 forkhead box P1

FOXP4 forkhead box P4

GATA4 GATA binding protein 4
GATA6 GATA binding protein 6

GCG glucagon

GEMM genetically engineered mouse model

GLI2 GLI family zinc finger 2

GLIS3 GLIS family zinc finger 3

HAS2 hyaluronic acid synthase 2

HDAC histone deacetylase

HES1 hairy and enhancer of split 1

HGF hepatocyte growth factor

HIF1A hypoxia inducible factor 1 subunit alpha

HKDC1 hexokinase domain containing 1

HNF1a hepatocyte nuclear factor 1 alpha

HNF1 $\beta$ hepatocyte nuclear factor 1 beta

HNF4a hepatocyte nuclear factor 4 alpha

HNF6 (Onecut1) hepatocyte nuclear factor 6 (one cut family member 1)

IFN interferon

INK4A/ARF cyclin-dependent kinase 4 Inhibitor/alternative

reading frame

INS1 insulin I

INS2 insulin II

INSM1 insulinoma-associated 1/INSM transcriptional repressor 1

IPMN intraductal papillary mucinous neoplasia

ISL1 islet 1/ISL LIM homeobox 1

JAK janus kinase

KDM6A lysine demethylase 6A

KITLG KIT ligand

KLF krüppel-like factor

KRAS KRAS proto-oncogene, GTPase

MAFA musculoaponeurotic fibrosarcoma oncogene homolog A/MAF bZIP transcription factor A

MAFB musculoaponeurotic fibrosarcoma oncogene homolog A/MAF bZIP transcription factor B

MAPK mitogen-activated protein kinase

MAZ MYC associated zinc finger protein

MCN mucinous cystic neoplasm

MET mesenchymal-epithelial transition

miRNA microRNA

MIST1 muscle, intestine and stomach expression 1/basic helix-loop-helix family member A15 (BHLHA15)

MMP matrix metalloprotease

MNX1 motor neuron and pancreas homeobox 1

MPC multipotent progenitor cell

mTOR mammalian target of rapamycin

MYC MYC proto-oncogene, bHLH transcription factor

NECTIN1 nectin cell adhesion molecule 1 
NEUROD1 neuronal differentiation 1

NFATC1 nuclear factor of activated T cells 1

NFATC4 nuclear factor of activated T cells 4

NFIX nuclear factor I X

NF- $\mathbf{k B}$ nuclear factor kappa B

NGN3 neurogenin 3

NKX2.2 NK2 homeobox 2

NKX6.1 NK6 homeobox 1

NR5A2 nuclear receptor subfamily 5 group A member 2

NSD2 nuclear receptor binding SET domain protein 2

p21(CIP/WAF1) cyclin-dependent kinase inhibitor 1/wild-type p53activated fragment 1

p53/TP53 tumor protein p53

p63/TP63 tumor protein p63

PaCa pancreatic cancer

PAK p21 activated kinase

PanIN pancreatic intraepithelial neoplasia

PAX4 paired box 4

PAX6 paired box 6

PcG polycomb group

PDAC pancreatic ductal adenocarcinoma

PDGF platelet-derived growth factor

PDX patient-derived tumor xenograft

PDX1 pancreatic and duodenal homeobox 1

PI3K phosphoinositide 3-kinases

PLK1 polo like kinase 1

POU3F4 POU class 3 homeobox 4

PRC2 polycomb repressor complex 2

PROX1 prospero homeobox 1

PRRX1 paired-related homeodomain transcription factor 1

PTF1A/p48 pancreas associated transcription factor 1a

RASA3 RAS $\mathrm{p} 21$ protein activator 3

RBPJL recombination signal binding protein for immunoglobulin kappa J region like
RFX3 regulatory factor X3

RFX6 regulatory factor X6

RNA ribonucleic acid

RUNX3 RUNX family transcription factor 3

SCA1 stem cell antigen 1

SE super-enhancer

SHH sonic hedgehog

SIX1 SIX homeobox 1

SIX4 SIX homeobox 4

SLUG/SNAI2 snail family transcriptional repressor 2

SMAD4/DPC4 SMAD family member 4/deleted in pancreatic cancer 4

SNAIL/SNAI1 snail family transcriptional repressor 1

SOX2 SRY-box transcription factor 2

SOX9 SRY-box transcription factor 9

SPARC secreted protein acidic and cysteine rich

SPP1 secreted phosphoprotein 1

SSBP3 single stranded DNA binding protein 3

STAT3 signal transducer and activator of transcription 3

TF transcription factor

TFIIH transcription factor IIH

TGFa transforming growth factor alpha

TGF $\beta$ transforming growth factor beta

TGIF1 TG-interacting factor 1

TJP1/ZO-1 tight junctional protein 1/zonula occludens 1

TPL triptolide

TWIST1 twist-related protein 1

VIM vimentin

WNT portmanteau from wingless and int-1 (locus of frequent mouse mammary tumor virus (MMTV) integration)

XPB/ERCC3 xeroderma pigmentosum type B/ERCC excision repair 3, TFIIH core complex helicase subunit

YAP Yes1 associated transcriptional regulator

ZEB1 zinc finger E-box binding homeobox 1

ZEB2 zinc finger E-box binding homeobox 2 